\title{
Seasonal variations of hydrogen peroxide and water vapor on Mars: Further indications of heterogeneous chemistry
}

\author{
T. Encrenaz ${ }^{1}$, T. K. Greathouse ${ }^{2}$, F. Lefèvre ${ }^{3}$, F. Montmessin ${ }^{3}$, F. Forget ${ }^{4}$, T. Fouchet ${ }^{1}$, C. DeWitt ${ }^{5}$, M. J. Richter ${ }^{5}$, \\ J. H. Lacy ${ }^{6}$, B. Bézard ${ }^{1}$, and S. K. Atreya ${ }^{7}$
}

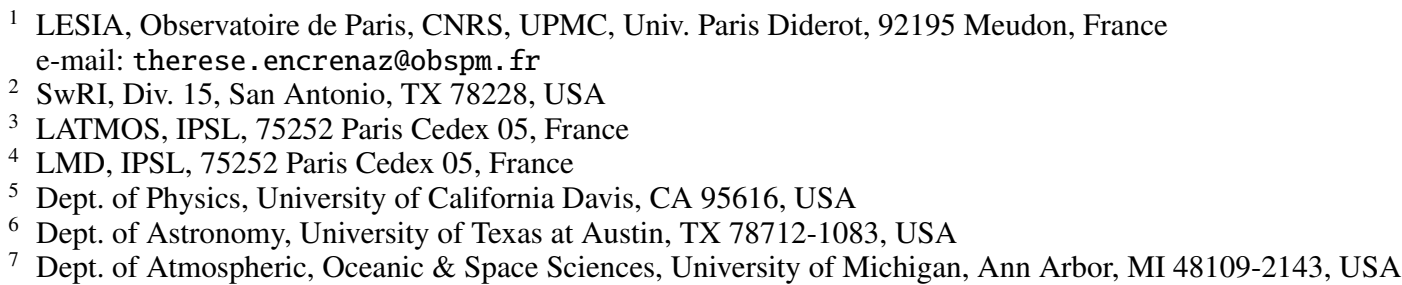

Received 2 December 2014 / Accepted 11 April 2015

\begin{abstract}
We have completed our seasonal monitoring of hydrogen peroxide and water vapor on Mars using ground-based thermal imaging spectroscopy, by observing the planet in March 2014, when water vapor is maximum, and July 2014, when, according to photochemical models, hydrogen peroxide is expected to be maximum. Data have been obtained with the Texas Echelon Cross Echelle Spectrograph (TEXES) mounted at the $3 \mathrm{~m}$-Infrared Telescope Facility (IRTF) at Maunakea Observatory. Maps of $\mathrm{HDO}$ and $\mathrm{H}_{2} \mathrm{O}_{2}$ have been obtained using line depth ratios of weak transitions of $\mathrm{HDO}$ and $\mathrm{H}_{2} \mathrm{O}_{2}$ divided by $\mathrm{CO}_{2}$. The retrieved maps of $\mathrm{H}_{2} \mathrm{O}_{2}$ are in good agreement with predictions including a chemical transport model, for both the March data (maximum water vapor) and the July data (maximum hydrogen peroxide). The retrieved maps of HDO are compared with simulations by Montmessin et al. (2005, J. Geophys. Res., 110, 03006) and $\mathrm{H}_{2} \mathrm{O}$ maps are inferred assuming a mean martian $\mathrm{D} / \mathrm{H}$ ratio of 5 times the terrestrial value. For regions of maximum values of $\mathrm{H}_{2} \mathrm{O}$ and $\mathrm{H}_{2} \mathrm{O}_{2}$, we derive, for March $12014\left(\mathrm{Ls}=96^{\circ}\right), \mathrm{H}_{2} \mathrm{O}_{2}=20+/-7 \mathrm{ppbv}, \mathrm{HDO}=450+/-75$ ppbv $(45+/-8$ pr-nm $)$, and for July $3,2014\left(\mathrm{Ls}=156^{\circ}\right), \mathrm{H}_{2} \mathrm{O}_{2}=30+/-7 \mathrm{ppbv}, \mathrm{HDO}=375+/-70$ ppbv $(22+/-3$ pr-nm $)$. In addition, the new observations are compared with LMD global climate model results and we favor simulations of $\mathrm{H}_{2} \mathrm{O}_{2}$ including heterogeneous reactions on water-ice clouds.
\end{abstract}

Key words. planets and satellites: atmospheres - planets and satellites: terrestrial planets - planets and satellites: individual: Mars

\section{Introduction}

Ever since the time of the Viking exploration, the presence of hydrogen peroxide in the Martian atmosphere has been suggested as an oxidizer of the Martian surface that could be responsible for the unexpected absence of organics. At that time, 1D globally averaged photochemical models also suggested the presence of hydrogen peroxide in limited amounts (too low to destroy the organics), at the level of a few tens of ppbv at maximum (see in particular Parkinson \& Hunten 1972; Atreya \& Gu 1995; Clancy \& Nair 1996). The observational detection of $\mathrm{H}_{2} \mathrm{O}_{2}$ was not easy. After over a decade of unsuccessful attempts, the detection of the molecule was first announced by Clancy et al. (2004) using heterodyne spectroscopy in the submillimeter range. A disk-integrated mixing ratio of $18 \mathrm{ppbv}$ was reported, in good agreement with the predictions of the photochemical models. At about the same time, $\mathrm{H}_{2} \mathrm{O}_{2}$ was detected and mapped using high-resolution imaging spectroscopy in the thermal infrared (Encrenaz et al. 2004). The seasonal behavior of $\mathrm{H}_{2} \mathrm{O}_{2}$ on Mars was subsequently monitored until 2009 (Encrenaz et al. 2005, 2008), and the dataset was compared with various photochemical models with and without heterogeneous chemistry (Encrenaz et al. 2012). This comparison was in favor of the heterogeneous model developed by Lefèvre et al. (2008). Unfortunately the data did not cover a critical season
$\left(\mathrm{Ls}=120-170^{\circ}\right)$ where the difference between the models is significant.

This paper reports new observations of $\mathrm{HDO}$ and $\mathrm{H}_{2} \mathrm{O}_{2}$ on Mars with TEXES, obtained in 2014 during two runs corresponding to critical values of the areocentric longitude: $\mathrm{Ls}=96^{\circ}$ near northern summer solstice (March 1, 2014) and Ls $=156^{\circ}$ in the middle of northern summer (July 3, 2014). The first run corresponds to the expected maximum level of water vapor concentrated around the north pole, and the second run corresponds to the expected maximum of the $\mathrm{H}_{2} \mathrm{O}_{2}$ abundance at low latitudes, according to the Global Climate Model (GCM) 3D models (Lefèvre et al. 2008). Section 2 describes the observations, the atmospheric modeling and the method used to retrieve the mixing ratios, also described in detail in the Appendix. Section 3 presents the results for $\mathrm{H}_{2} \mathrm{O}_{2}$ and $\mathrm{HDO}$ for the March run and the July run, respectively. In Sect. 4, the results are discussed and compared with photochemical models. Section 5 summarizes our conclusions.

\section{Observations and data analysis}

\subsection{TEXES observations}

The Texas Echelon Cross Echelle Spectrograph (TEXES) is an imaging spectrometer operating between 5 and $25 \mu \mathrm{m}$ 


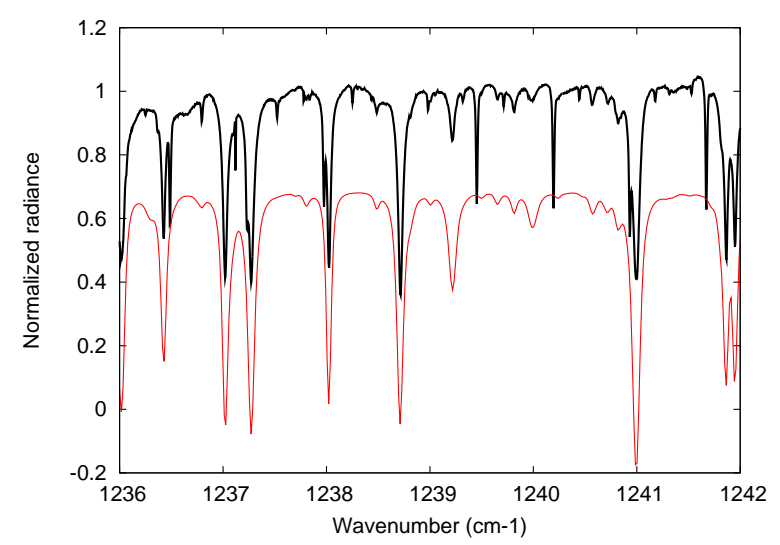

Fig. 1. Thick black line: spectrum of Mars between 1236 and $1242 \mathrm{~cm}^{-1}$, integrated over the Martian disk, recorded on July 3, 2014 (Ls $=156^{\circ}$, normalized radiance). Thick red line (in absolute units shifted by -0.30$)$ : Transmission from the terrestrial atmosphere, computed with the Gemini Observatory model $\left(\mathrm{H}_{2} \mathrm{O}=1 \mathrm{pr}-\mathrm{mm}\right)$.

that combines a high resolving power (about 70000 at $8 \mu \mathrm{m}$ in the high-resolution mode) and a good spatial resolution (about 1 arcsec). A full description of the instrument can be found in Lacy et al. (2002). We used the instrument at the $3 \mathrm{~m}$ Infrared Telescope Facility (IRTF) at Maunakea Observatory (Hawaii). As we did for our previous observations (Encrenaz et al. 2012), we used the 1237-1242 $\mathrm{cm}^{-1}$ spectral range $(8.05-8.08 \mu \mathrm{m})$ where weak transitions of $\mathrm{CO}_{2}, \mathrm{HDO}$ and $\mathrm{H}_{2} \mathrm{O}_{2}$ are found. We used a $1.1 \times 8$ arcsec slit, aligned along the celestial north-south axis, and we stepped the telescope by 0.5 arcsec in the west-east direction between two successive integrations in order to map the Martian disk.

Observations took place during two runs: (1) March 1, 2014, 12:00-14:00 UT $\left(\mathrm{Ls}=96^{\circ}\right.$, near northern summer solstice) and (2) July 2-4, 2014, 16:00-19:00 UT (Ls $=156^{\circ}$, middle of northern summer). The diameter of Mars was 11.6 arcsec and 9.4 arcsec in March and July respectively, so in both cases we scanned the northern and the southern hemispheres successively to obtain a full map. The time needed to record a full map, including both hemispheres, was about $15 \mathrm{~min}$. An example of disk-integrated spectrum, corresponding to a two-hour integrating time on July 3, 2014, is shown in Fig. 1. Doppler velocities were $-13.4 \mathrm{~km} \mathrm{~s}^{-1}$ and $+11.5 \mathrm{~km} \mathrm{~s}^{-1}$ on March 1, 2014 and July 3, 2014 corresponding (at $1240 \mathrm{~cm}^{-1}$ ) to Doppler shifts of $+0.054 \mathrm{~cm}^{-1}$ and $-0.0475 \mathrm{~cm}^{-1}$, respectively. The TEXES data cubes are calibrated using the radiometric method commonly used for submillimeter/millimeter astronomy (Rohlfs \& Wilson 2004), which is described in detail in Lacy et al. (2002).

For both datasets, the Martian disks had a comparable size (about 10 arcsec) and a high illumination factor (above $87 \%$ ), but the local times were very different. In March 2014 the evening terminator was observed, while in July 2014 the morning terminator was in the field of view. This latter configuration (observation of a significant night crescent and morning terminator) was not observed in any of our previous runs (Encrenaz et al. 2012). As will be discussed below, this has an important effect on the structure of the thermal profile before and around dawn, and on our ability to retrieve mixing ratios of minor species.

As in the case of our previous observations, we selected weak transitions of $\mathrm{HDO}, \mathrm{H}_{2} \mathrm{O}_{2}$ and $\mathrm{CO}_{2}$, well isolated from telluric lines. In the case of $\mathrm{HDO}$, we selected transitions at $1237.077 \mathrm{~cm}^{-1}\left(\left[\begin{array}{llllll}0 & 1 & 0,4 & 4 & 2\end{array}\right]-\left[\begin{array}{llllll}0 & 0 & 0, & 5 & 4 & 1\end{array}\right] ; I=6.49 \times\right.$ $\left.10^{-24} \mathrm{~cm} \mathrm{molec}^{-1}, E=480.259 \mathrm{~cm}^{-1}\right)$ and $1236.295 \mathrm{~cm}^{-1}$

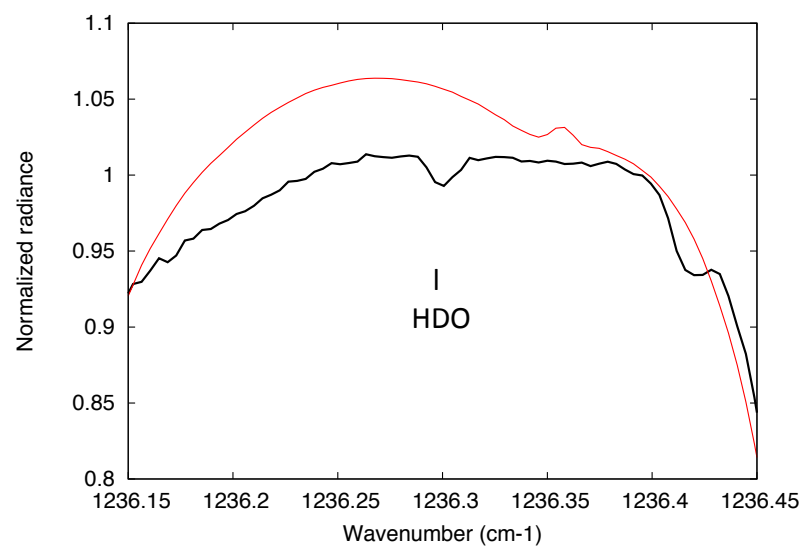

Fig. 2. Thick black line: HDO transition on Mars between 1236.15 and $1236.45 \mathrm{~cm}^{-1}$, integrated over the Martian disk, recorded on July 3, 2014 (Ls $=156^{\circ}$, normalized radiance). Thick red line: normalized atmospheric transmission as measured by the TEXES instrument.

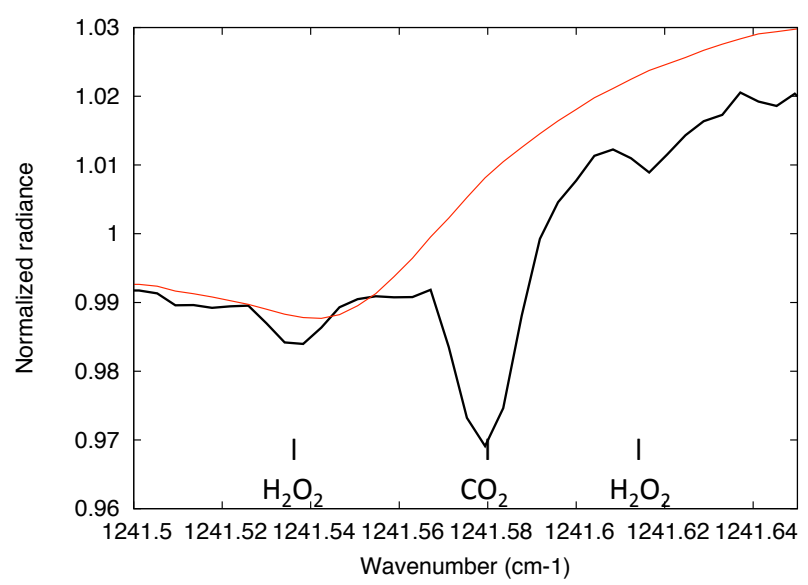

Fig. 3. Thick black line: $\mathrm{H}_{2} \mathrm{O}_{2}$ transitions on Mars between 1241.50 and $1241.65 \mathrm{~cm}^{-1}$, integrated over the Martian disk, recorded on July 3, 2014 (Ls $=156^{\circ}$, normalized radiance). Thick red line: Normalized atmospheric transmission as measured by the TEXES instrument.

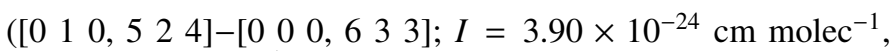
$E=469.664 \mathrm{~cm}^{-1}$ ) in March and July respectively. Figure 2 shows the $1236.3 \mathrm{~cm}^{-1}$ transition of HDO integrated over the disk on July 3 . The $1237.08 \mathrm{~cm}^{-1}$ transition was not usable in the July data owing to an instrumental spike that occurred exactly at this frequency. Both HDO lines have intensities corresponding to line depths of a few percent. For both runs we used the $\mathrm{H}_{2} \mathrm{O}_{2}$ doublet of the $v_{6}$ band at $1241.533 \mathrm{~cm}^{-1}(I=3.600 \times$ $\left.10^{-20} \mathrm{~cm} \mathrm{molec}{ }^{-1}, E=155.502 \mathrm{~cm}^{-1}\right)$ and $1241.613 \mathrm{~cm}^{-1}$ $\left(I=3.370 \times 10^{-20} \mathrm{~cm} \mathrm{molec}^{-1}, E=163.185 \mathrm{~cm}^{-1}\right)$, which brackets a weak $\mathrm{CO}_{2}$ isotopic (628) transition at $1241.58 \mathrm{~cm}^{-1}$ (Fig. 3); the $\mathrm{CO}_{2}$ line is a very close doublet at $1241.574 \mathrm{~cm}^{-1}$ and $1241.580 \mathrm{~cm}^{-1}$, (with $I=5.200 \times 10^{-27} \mathrm{~cm} \mathrm{molec}^{-1}$ and $E=664.59 \mathrm{~cm}^{-1}$ for each transition). In Figs. 2 and 3, the atmospheric transmission, as observed by the TEXES instrument, is shown for comparison. For both lines it can be seen that the shape of the continuum, on both sides of the lines, shows the same trend as the atmospheric transmission. However, the fit is not good enough to correct the continuum fluctuations by making the ratio of the Mars spectrum by the atmospheric transmission curve, implying that additional fluctuations of instrumental origin remain in the continuum. It can be seen from the data that these fluctuations are not constant over the disk but vary from pixel to pixel. Given lack of accurate modeling of these 
fluctuations, we have measured the line depths by using, for the continuum of each line, a straight line between the continuum fluxes measured on each side of this line. This simple method has the advantage of making no a priori assumption on the nature of the fluctuations.

The $\mathrm{HDO}$ and $\mathrm{H}_{2} \mathrm{O}_{2}$ mixing ratios were estimated from the ratios of the line depths of the $\mathrm{HDO}$ and $\mathrm{H}_{2} \mathrm{O}_{2}$ lines divided by the $\mathrm{CO}_{2}$ line depth. As discussed in earlier papers (see Encrenaz et al. 2008), this first-order method minimizes the uncertainties associated with the surface and atmospheric parameters, as well as the airmass factor. In the present paper, we present a full analysis of the uncertainties associated with this method (see Sect. 3.3 and Appendix). Other uncertainty sources (noise level, calibration accuracy, pointing and limb positioning accuracy) are also discussed below (Sects. 3.1.1, 3.2.1 and 3.3). As in our previous studies, our mixing ratios, expressed by volume, are derived relative to carbon dioxide.

\subsection{Data interpretation and modeling}

The continuum radiance (at $1341.6 \mathrm{~cm}^{-1}$ ) and the line depths of the selected transitions were measured in each pixel, and maps of these parameters were extracted from the data cubes. Maps of the line depth ratios were obtained in all regions of the Martian disk where (1) the continuum level was significantly above the noise level (larger than $5 \mathrm{erg} / \mathrm{s} / \mathrm{cm}^{2} / \mathrm{sr} / \mathrm{cm}^{-1}$ ), and (2) the $\mathrm{CO}_{2}$ line depth was positive and above the noise level (larger than 0.02). Our criteria excluded the regions where the temperature profile is quasi-isothermal or even shows an inversion. As will be presented below, this case happens late in the evening in the case of the March observations, and on the night side and at dawn near the morning terminator in the case of the July observations. We decided to also remove the regions on the night side where both the $\mathrm{CO}_{2}$ and the minor species showed emission lines because there may be some uncertainty if lines are formed at slightly different altitude levels.

On the basis of the maps, we selected regions where the $\mathrm{HDO}$ and $\mathrm{H}_{2} \mathrm{O}_{2}$ mixing ratios were highest, and compared the spectra in these regions with synthetic models. As a first guess, we used the atmospheric parameters (surface pressure, surface temperature, and thermal profile) inferred from the Global Climate Model (GCM, Forget et al. 1999). We then used the $\mathrm{CO}_{2}$ transitions to get the best fit by slightly adjusting these parameters, and we used them to model the HDO and $\mathrm{H}_{2} \mathrm{O}_{2}$ transitions. Calculations show that for all transitions the lines are mostly formed in the lower troposphere, within the first ten kilometers above the surface.

Our synthetic spectra were modeled using spectroscopic data extracted from the GEISA molecular database (Jacquinet-Husson et al. 2008). In addition, weak $\mathrm{CO}_{2}$ isotopic transitions were added using the analysis of Rothman (1986). In the case of HDO, water vapor was inferred in a next step, assuming a Martian $\mathrm{D} / \mathrm{H}$ mixing ratio of 5 times the terrestrial value, on the basis of previous observational estimates (this assumption is discussed in more detail in Sect. 4.2). We note, however, that this ratio is expected to show variations over the Martian disk with latitude and season (Montmessin et al. 2005; Novak et al. 2012; Villanueva et al. 2015), and a more accurate measurement of the $\mathrm{D} / \mathrm{H}$ ratio on Mars for all seasons remains to be achieved.

As in our previous analyses, we have assumed for both $\mathrm{H}_{2} \mathrm{O}$ and $\mathrm{H}_{2} \mathrm{O}_{2}$ a constant mixing ratio as a function of altitude. The spectral resolution of TEXES does not allow us to have access to the true profiles of the minor species; only heterodyne spectroscopy with a resolving power of $10^{6}$ would deliver this

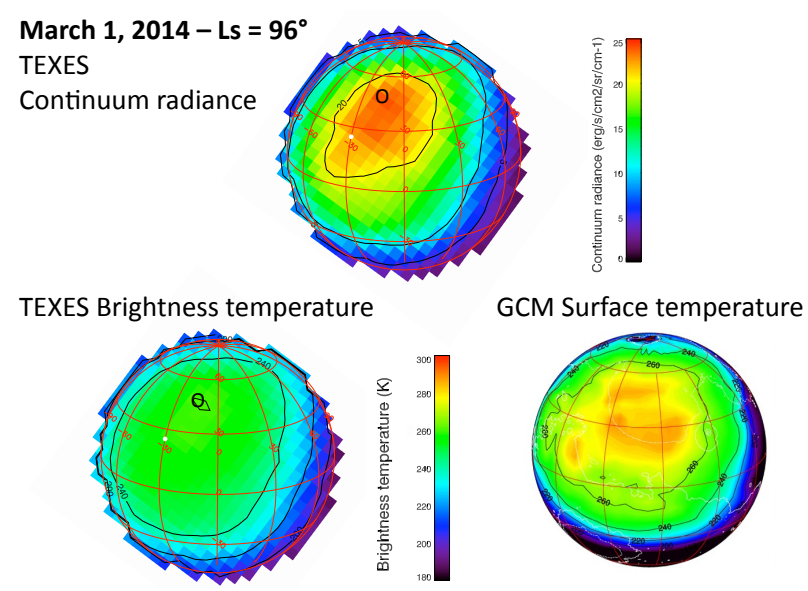

Fig. 4. Top: continuum radiance map of the Martian disk recorded at $1241.50 \mathrm{~cm}^{-1}$ on March 1, $2014\left(\mathrm{Ls}=96^{\circ}\right)$. Bottom left: brightness temperature TEXES map converted from the radiance map, assuming a surface emissivity of 1.0. The subsolar point is indicated with a white dot. The black circle corresponds to Region A where the TEXES spectra were modeled (see text). Bottom right: synthetic map of the surface temperature retrieved from the GCM under similar observing conditions.

information. In addition, the line depth ratio method gives the measurement of the mixing ratios of the minor species versus $\mathrm{CO}_{2}$ assuming the same scale height for all molecules. The consequences of this approximation are analyzed in the discussion (Sects. 4.1.4 and 4.2.3).

\section{Results}

\subsection{Northern summer solstice ( $L s=96^{\circ}$, March 1, 2014)}

\subsubsection{Continuum radiance and surface temperature}

Figure 4 shows a map of the continuum radiance, measured at $1241.50 \mathrm{~cm}^{-1}$. We convert the radiance into brightness temperature to compare it with a map of the surface temperature for the same date and under the same geometrical conditions extracted from the GCM. Assuming no extinction by dust and clouds, the continuum radiance gives us the product $\epsilon \times \mathrm{BB}(\mathrm{Ts})$, where $\mathrm{BB}(\mathrm{Ts})$ is the blackbody corresponding to the surface temperature and $\epsilon$ is the surface emissivity. Comparison of this quantity with the predicted GCM surface temperature gives us information about the surface emissivity and the possible extinction from the atmosphere (dust and clouds).

It can be seen that the two maps are in good agreement in terms of global distribution over the disk. However, in the region of maximum flux, the TEXES brightness temperature is lower than the GCM prediction by about $20 \mathrm{~K}$, corresponding to a decrease in radiance of about $60 \%$. The difference between the TEXES brightness temperature and the GCM surface temperature can be due to three factors: the surface emissivity $\epsilon$, the extinction by airborne dust and the extinction by water ice clouds. The surface emissivity at $1240 \mathrm{~cm}^{-1}$ is known to be higher than 0.90 (Christensen et al. 2001). The dust opacity in the northern hemisphere for Ls $=96^{\circ}$ is expected to be very low (Smith 2004). In contrast, the presence of water ice clouds is likely in this season, especially for low and middle latitudes (Smith 2004). Thus, the difference between the observed and expected radiances in the region of maximum is most likely the result of cloud extinction. As this effect acts as a gray screen at high altitude (above the lower troposphere where the lines are 

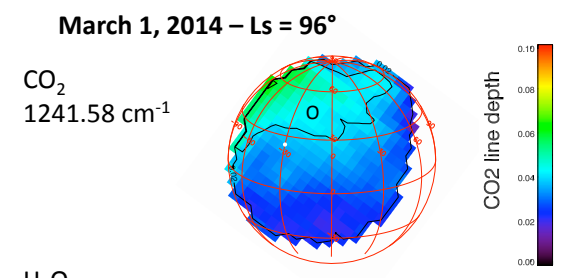

$1241.53 \mathrm{~cm}^{-1}$

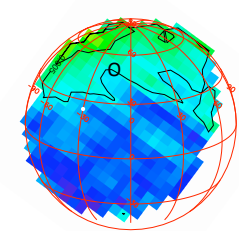

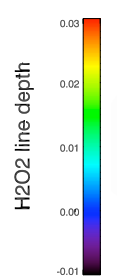

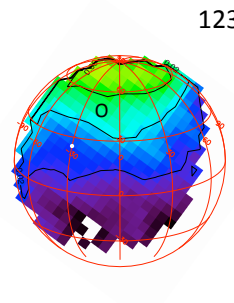

HDO

$1237.08 \mathrm{~cm}^{-1}$

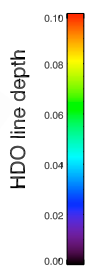

Fig. 5. Maps of the line depths for $\mathrm{CO}_{2}\left(1241.58 \mathrm{~cm}^{-1}\right)$, HDO $\left(1237.07 \mathrm{~cm}^{-1}\right)$ and $\mathrm{H}_{2} \mathrm{O}_{2}\left(1241.53 \mathrm{~cm}^{-1}\right)$ recorded on March 1, 2014 $\left(\mathrm{Ls}=96^{\circ}\right)$. The measurement is not reliable at the evening terminator and on the night side because the continuum is too low.

formed), it is not expected to affect the line depths of the spectrum, and a fortiori their line depth ratios.

\subsection{2. $\mathrm{H}_{2} \mathrm{O}_{2}$ and $\mathrm{HDO}$ mixing ratios}

Figure 5 shows the maps of the line depths of $\mathrm{CO}_{2}$ $\left(1241.58 \mathrm{~cm}^{-1}\right), \quad \mathrm{HDO}\left(1237.08 \mathrm{~cm}^{-1}\right)$ and $\mathrm{H}_{2} \mathrm{O}_{2}$ $\left(1241.53 \mathrm{~cm}^{-1}\right)$. The $\mathrm{CO}_{2}$ map indicates a maximum in the northern hemisphere in the morning and around noon. It illustrates both a maximum of the surface temperature in this region as shown in Fig. 4 and an airmass effect at the morning limb, also associated with a topography effect. These maps, together with Fig. 4, indicate the regions of the Martian disk where the $\mathrm{HDO}$ and $\mathrm{H}_{2} \mathrm{O}_{2}$ mixing ratios can be retrieved; the evening regions and the night side are excluded because the continuum is too low.

$\mathrm{H}_{2} \mathrm{O}_{2}$

Figure 6 shows a map of the $\mathrm{H}_{2} \mathrm{O}_{2} / \mathrm{CO}_{2}$ line depth ratio, retrieved from the TEXES maps shown in Fig. 5. As explained in detail in the Appendix, in the case of $\mathrm{H}_{2} \mathrm{O}_{2}$, the line depth ratio can be converted into the mixing ratio of the molecule with an accuracy of a few percent all over the disk. We convert this unit into the $\mathrm{H}_{2} \mathrm{O}_{2}$ mixing ratio per volume, using the relationship

$\operatorname{mr}\left(\mathrm{H}_{2} \mathrm{O}_{2}\right)=\operatorname{ldr}\left(\mathrm{H}_{2} \mathrm{O}_{2}\right) \times 40 . / 0.29 /[1.0+(\mathrm{am}-1.0) \times 0.025]$,

where $\mathrm{mr}$ is the mixing ratio, ldr the line depth ratio and am the airmass. This equation, discussed in the Appendix, includes a correction for the airmass. Our map is then compared with a map of the column averaged $\mathrm{H}_{2} \mathrm{O}_{2}$ mixing ratio retrieved from the GCM under the same observing conditions. It can be seen that there is a good overall agreement between the two maps: as expected at the time of northern summer solstice, the hydrogen peroxide content is highest at high northern latitudes with a mixing ratio of about 30-40 ppbv. We note, however, a discrepancy in the fine structure of the $\mathrm{H}_{2} \mathrm{O}_{2}$ spatial distribution in this region: the TEXES data indicate a maximum around the pole while the GCM predicts a maximum at latitudes around $60 \mathrm{~N}$.

Following the method developed in previous studies (Encrenaz et al. 2004, 2005, 2012), we used the TEXES map of $\mathrm{H}_{2} \mathrm{O}_{2}$ to isolate a region at high northern latitude (region A) corresponding to a high $\mathrm{H}_{2} \mathrm{O}_{2}$ content. Area A, located around $50 \mathrm{~N}$ at a local time of 13:00, is chosen near noon in order to maximize
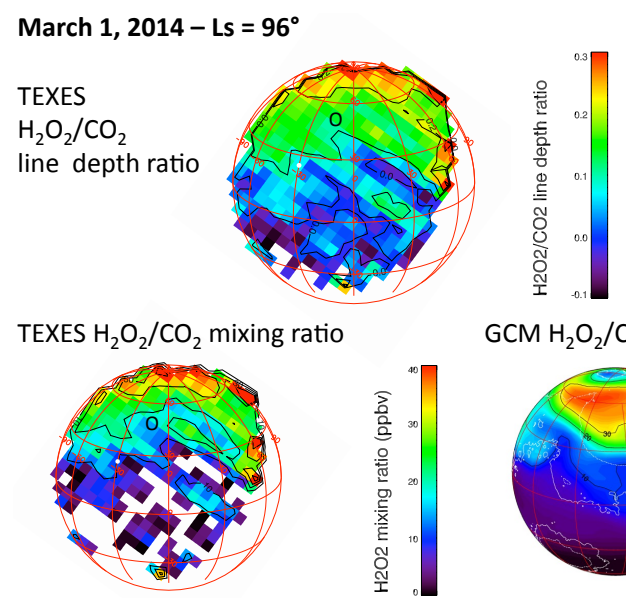

Fig. 6. Top: map of the line depth ratio of $\mathrm{H}_{2} \mathrm{O}_{2} / \mathrm{CO}_{2}$ retrieved from the TEXES data recorded on March 1, $2014\left(\mathrm{Ls}=96^{\circ}\right)$. The black circle corresponds to region A where the TEXES spectra were modeled (see text). Bottom left: map of the TEXES $\mathrm{H}_{2} \mathrm{O}_{2} / \mathrm{CO}_{2}$ mixing ratio, in ppbv, derived from the $\mathrm{H}_{2} \mathrm{O}_{2} / \mathrm{CO}_{2}$ line depth ratio. Bottom right: GCM synthetic map of the $\mathrm{H}_{2} \mathrm{O}_{2} / \mathrm{CO}_{2}$ column-averaged mixing ratio calculated for the same observing conditions.

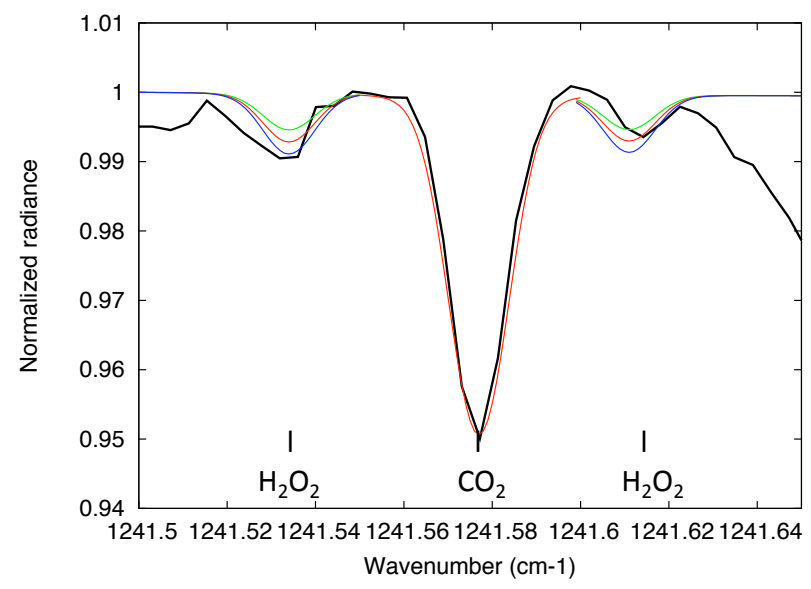

Fig. 7. Thick black line: TEXES spectrum of Mars in the vicinity of $\mathrm{H}_{2} \mathrm{O}_{2}$ and $\mathrm{CO}_{2}$ lines around $1241.58 \mathrm{~cm}^{-1}$ (March 1, 2014, $\mathrm{Ls}=96^{\circ}$ ), integrated over Region A (9 pixels), compared with synthetic spectra. The continuum fluctuation in the TEXES data was corrected by using the continuum on each side of each line and assuming a straight line between these two points. The airmass is 1.20. Models: $\mathrm{H}_{2} \mathrm{O}_{2}=15 \mathrm{ppbv}$ (green), 20 ppbv (red), 25 ppbv (blue). The best fit is obtained for $\mathrm{H}_{2} \mathrm{O}_{2}=20$ ppbv.

the continuum level and to optimize the signal-to-noise ratio of the data. We modeled the $\mathrm{H}_{2} \mathrm{O}_{2}$ and $\mathrm{CO}_{2}$ lines in this region to infer the hydrogen peroxide content. Starting from the GCM atmospheric parameters corresponding to this region and using the appropriate air mass, we first adjusted these parameters to fit the $\mathrm{CO}_{2}$ transition at $1241.58 \mathrm{~cm}^{-1}$. Our thermal profile has temperatures of $236 \mathrm{~K}, 205 \mathrm{~K}, 166 \mathrm{~K}$ and $155 \mathrm{~K}$ at altitudes of $0 \mathrm{~km}$, $10 \mathrm{~km}, 30 \mathrm{~km}$, and $50 \mathrm{~km}$, respectively. We used a surface pressure of 8.3 mbar and a surface brightness temperature of $250 \mathrm{~K}$. This profile is also shown in the Appendix (Fig. 17). Then, we adjusted the $\mathrm{H}_{2} \mathrm{O}_{2}$ mixing ratio to fit the $\mathrm{H}_{2} \mathrm{O}_{2}$ doublet. The result is shown in Fig. 7. It can be seen that the best fit corresponds to a $\mathrm{H}_{2} \mathrm{O}_{2}$ mixing ratio of 20 ppbv. This result is discusssed and compared with 3D-photochemical simulations in Sect. 4. 
March 1, 2014-Ls $=96^{\circ}$

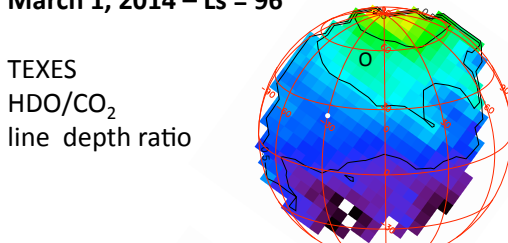

TEXES $\mathrm{HDO} / \mathrm{CO}_{2}$ mixing ratio

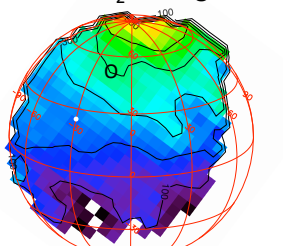

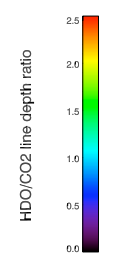

$\mathrm{GCM} \mathrm{HDO} / \mathrm{CO}_{2}$ mixing ratio
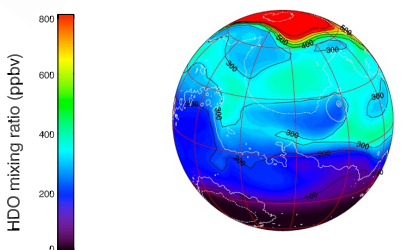

Fig. 8. Top: map of the line depth ratio of $\mathrm{HDO} / \mathrm{CO}_{2}$ retrieved from the TEXES data recorded on March 1, $2014\left(\mathrm{Ls}=96^{\circ}\right)$. The black circle corresponds to Region A where the TEXES spectra were modeled (see text). Bottom left: TEXES map of the $\mathrm{HDO} / \mathrm{CO}_{2}$ mixing ratio inferred from the $\mathrm{HDO} / \mathrm{CO}_{2}$ line depth ratio. Bottom right: GCM synthetic map of the HDO mixing ratio, in ppbv, under the same observing conditions.

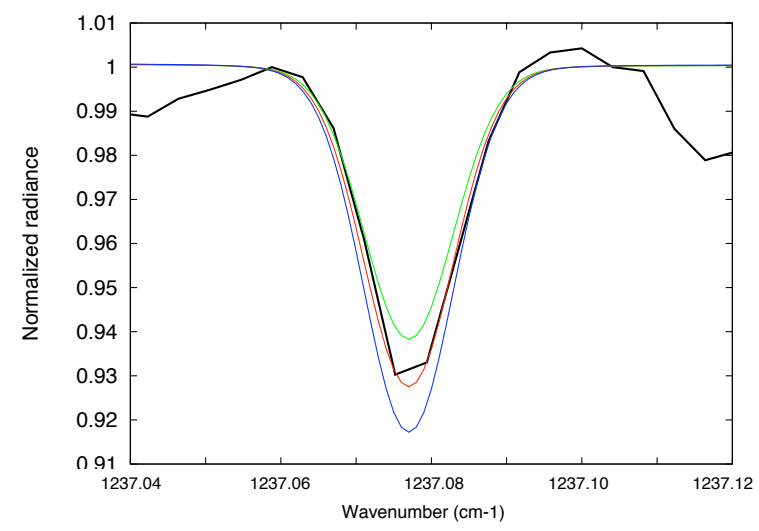

Fig. 9. Thick black line: TEXES spectrum of Mars near the HDO line in the vicinity of $1237.08 \mathrm{~cm}^{-1}$, integrated over Region A (9 pixels), compared with synthetic spectra (March 1, 2014; Ls $=96^{\circ}$ ). The continuum fluctuation in the TEXES data has been corrected by using the continuum on each side of each line and assuming a straight line between these two points. The airmass is 1.20 . Models: $\mathrm{H}_{2} \mathrm{O}=375 \mathrm{ppbv}$ (green), $450 \mathrm{ppbv}$ (red), $525 \mathrm{ppbv}$ (blue). The best fit is obtained for $\mathrm{HDO}=450$ ppbv.

\section{HDO}

Figure 8 shows a map of the $\mathrm{HDO} / \mathrm{CO}_{2}$ line depth ratio, retrieved from the TEXES maps shown in Fig. 4 and a map of the HDO mixing ratio calculated using the formula

$\operatorname{mr}($ HDO $)=\operatorname{ldr}($ HDO $) \times 600.0 / 1.9$

where $\mathrm{mr}$ is the mixing ratio and ldr the line depth ratio (see Appendix). Then we compare this map with a map of the HDO column density retrieved from the GCM and the simulations of Montmessin et al. (2005) under the same observing conditions. These maps are discussed in Sect. 4.

We used the same area as defined above to infer the HDO water content at high northern latitude (Area A). We modeled the HDO spectrum using the surface parameters, the thermal profile, and the airmass factor defined for the $\mathrm{H}_{2} \mathrm{O}_{2}$ study. The result is shown in Fig. 9. The best fit is obtained for a HDO mixing ratio of $450 \mathrm{ppbv}$, corresponding to a column density of $45 \mathrm{pr}-\mathrm{nm}$. This result is discussed in Sect. 4.

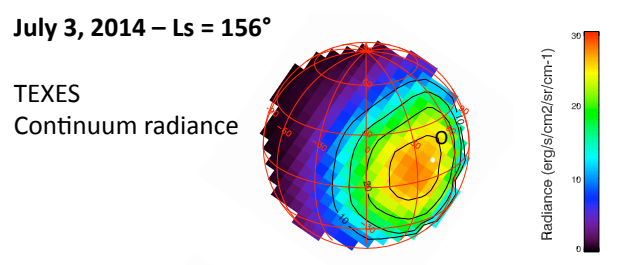

TEXES Brightness temperature
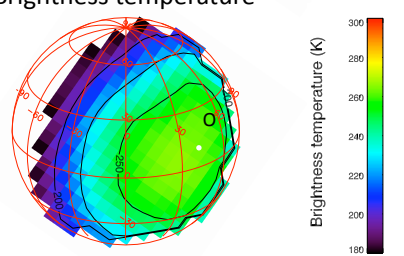

GCM Surface temperature

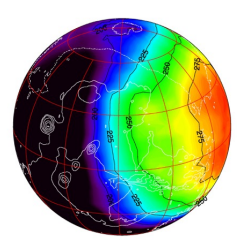

Fig. 10. Top: continuum radiance map of the Martian disk recorded at $1241.50 \mathrm{~cm}^{-1}$ on July 3, $2014\left(\mathrm{Ls}=156^{\circ}\right)$. Bottom left: TEXES map of the brightness temperatures inferred from the radiance map, assuming a surface emissivity of 1.0. The subsolar point is indicated with a white dot. The black circle corresponds to Region B where the TEXES spectra were modeled (see text). Bottom right: synthetic map of the surface temperature retrieved from the GCM under similar observing conditions.

\subsection{Southern summer ( $L s=156^{\circ}$, July 3, 2014)}

Data were recorded over three successive nights (July 2, 3, and 4, 2014, between 16:00 and 19:00 UT). Data cubes were acquired over the disk of Mars in the $1236-1242 \mathrm{~cm}^{-1}$ range. Maps of the continuum radiance and the line depths of $\mathrm{CO}_{2}$, $\mathrm{HDO}$ and $\mathrm{H}_{2} \mathrm{O}_{2}$ were very similar over the three nights, leading to identical maps of the $\mathrm{H}_{2} \mathrm{O}_{2}$ and $\mathrm{HDO}$ mixing ratios. We present below the results obtained on July 3, 2014.

\subsubsection{Continuum radiance and surface temperature}

Figure 10 shows the continuum radiance map of Mars for July 3, 2014. This map is converted in brightness temperature and compared with a map of the surface temperature extracted from the GCM under the same observing conditions. As in the case of the March data, the general agreement is good, except near the limb in the afternoon where the maximum radiance expected in the GCM is not observed by TEXES. We note that, in the case of the TEXES map, there may be an uncertainty associated with the definition of the limb; because of the low temperatures on the night side, the map was far from being spherical. The limb was defined using both the continuum and the $\mathrm{CO}_{2}$ line depth maps; however, the precision was limited by the quality of the seeing (not better than 1 arcsec), which translates into about two hours in local time at the limb near the equator. More important, the convolution by the 1-arcsec seeing has the effect of decreasing the flux in the limb pixels, which explains most of the difference between the TEXES and GCM maps at the limb. We also note that in southern summer $\left(\mathrm{Ls}=156^{\circ}\right)$ some dust may be expected in the atmosphere (Smith 2004). Clouds and dust extinction, associated with the high airmass, are probably responsible for the observed cooling near the limb, not predicted in the GCM surface temperature map. As in the case of the March 2014 data, the extinction by dust and/or clouds should have no incidence on the retrieval of the $\mathrm{H}_{2} \mathrm{O}_{2}$ and HDO mixing ratios.

\subsection{2. $\mathrm{H}_{2} \mathrm{O}_{2}$ and $\mathrm{HDO}$ mixing ratios}

Figure 11 shows the maps of the line depths of $\mathrm{CO}_{2} \quad\left(1241.58 \mathrm{~cm}^{-1}\right), \quad \mathrm{HDO}\left(1236.30 \mathrm{~cm}^{-1}\right)$, and $\mathrm{H}_{2} \mathrm{O}_{2}$ 


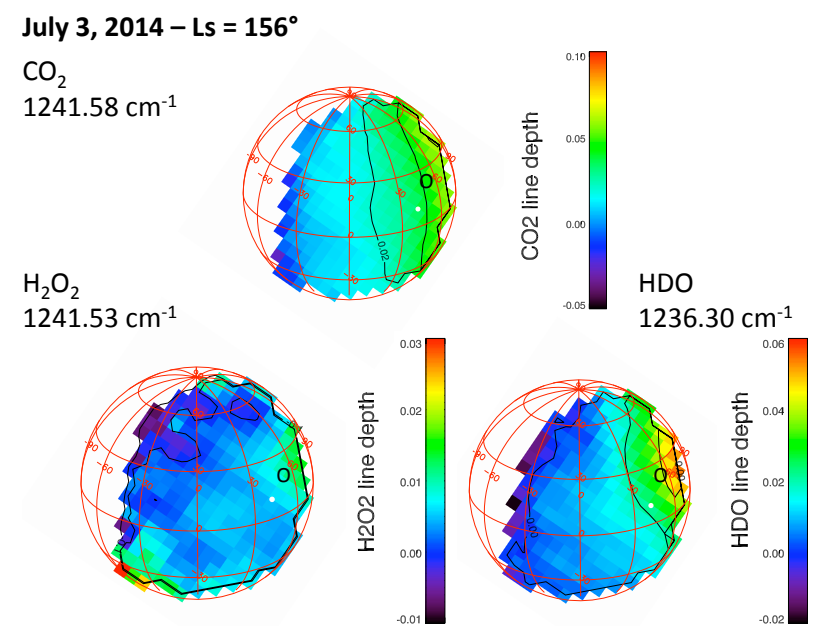

Fig. 11. Maps of the line depth of $\mathrm{CO}_{2}\left(1241.58 \mathrm{~cm}^{-1}\right)$, HDO $\left(1236.30 \mathrm{~cm}^{-1}\right)$ and $\mathrm{H}_{2} \mathrm{O}_{2}\left(1241.53 \mathrm{~cm}^{-1}\right)$ recorded on July 3, 2014 $\left(\mathrm{Ls}=156^{\circ}\right)$. The measurement is not reliable on the night side or near dawn because the continuum is too low.

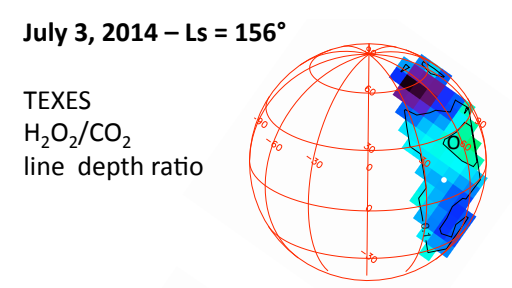

TEXES $\mathrm{H}_{2} \mathrm{O}_{2} / \mathrm{CO}_{2}$ mixing ratio
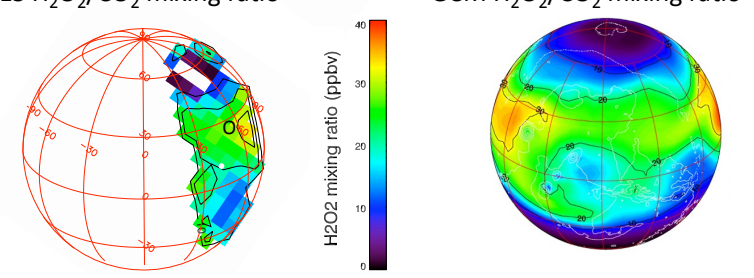

$\mathrm{GCM} \mathrm{H} \mathrm{O}_{2} / \mathrm{CO}_{2}$ mixing ratio

Fig. 12. Top: map of the line depth ratio of $\mathrm{H}_{2} \mathrm{O}_{2} / \mathrm{CO}_{2}$ retrieved from the TEXES data recorded on July 3, $2014\left(\mathrm{Ls}=156^{\circ}\right)$. The black circle corresponds to Region B where the TEXES spectra were modeled (see text). Bottom left: map of the TEXES $\mathrm{H}_{2} \mathrm{O}_{2} / \mathrm{CO}_{2}$ mixing ratio, inferred from the $\mathrm{H}_{2} \mathrm{O}_{2} / \mathrm{CO}_{2}$ line depth ratio map. Bottom right: GCM synthetic map of the $\mathrm{H}_{2} \mathrm{O}_{2}$ column-averaged mixing ratio calculated for the same observing conditions.

$\left(1241.53 \mathrm{~cm}^{-1}\right)$. The $\mathrm{CO}_{2}$ map indicates a maximum around noon and in the afternoon. It illustrates both a maximum of the surface temperature in this region (Fig. 10), hence a maximum temperature contrast between the surface and the atmosphere, and an airmass effect at the afternoon limb. On the night side and near dawn, the HDO and $\mathrm{H}_{2} \mathrm{O}_{2}$ mixing ratios cannot be retrieved because the continuum is too low and the $\mathrm{CO}_{2}$ line depth is too weak.

$$
\mathrm{H}_{2} \mathrm{O}_{2}
$$

Figure 12 shows a map of the $\mathrm{H}_{2} \mathrm{O}_{2} / \mathrm{CO}_{2}$ mixing ratio inferred from the line depths shown in Fig. 11. The map is translated into $\mathrm{H}_{2} \mathrm{O}_{2}$ mixing ratios, using the formula given in the Appendix, and compared with the GCM map corresponding to the same observing conditions. Unfortunately, the TEXES map is limited to a small portion of the Martian disk, because the $\mathrm{CO}_{2}$ line depth, and a fortiori the $\mathrm{H}_{2} \mathrm{O}_{2}$ line depth, are close to zero for all local times earlier than 11:00 am. In the region of the disk where the $\mathrm{H}_{2} \mathrm{O}_{2}$ content can be measured, the agreement with the GCM map is good, with a local maximum

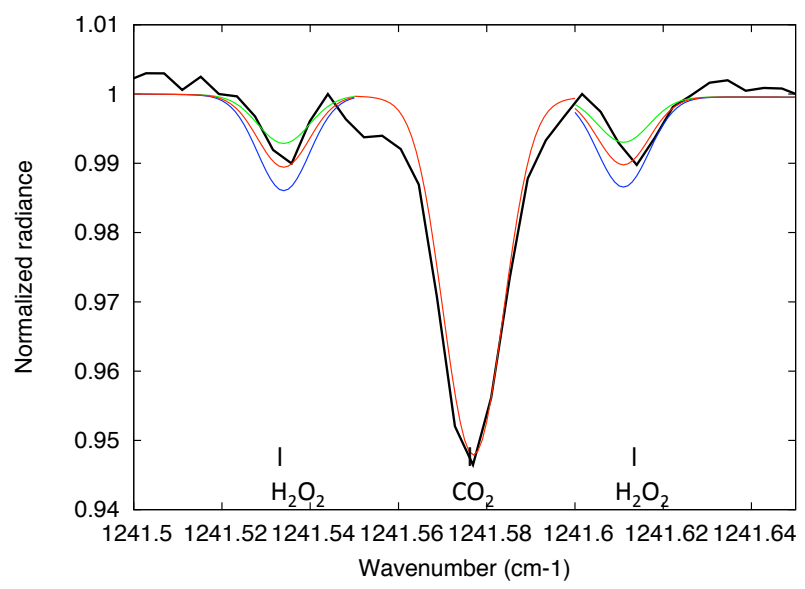

Fig. 13. Thick black line: TEXES spectrum of Mars in the vicinity of the $\mathrm{H}_{2} \mathrm{O}_{2}$ and $\mathrm{CO}_{2}$ around $1241.58 \mathrm{~cm}^{-1}$ (July 3, 2014), integrated over Region B (9 pixels), compared with synthetic spectra (July 3, 2014; $\mathrm{Ls}=156^{\circ}$ ). The continuum fluctuation in the TEXES data has been corrected by using the continuum on each side of each line and assuming a straight line between these two points. The airmass is 1.55. Models: $\mathrm{H}_{2} \mathrm{O}_{2}=20 \mathrm{ppbv}$ (green), 30 ppbv (red), $40 \mathrm{ppbv}$ (blue). The best fit is obtained for $\mathrm{H}_{2} \mathrm{O}_{2}=30$ ppbv.

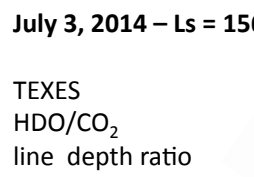

TEXES $\mathrm{HDO} / \mathrm{CO}_{2}$ mixing ratio

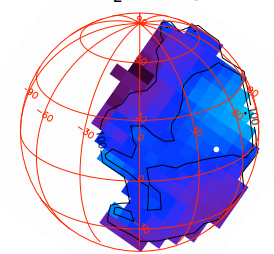

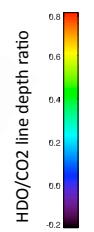

$\mathrm{GCM} \mathrm{HDO} / \mathrm{CO}_{2}$ mixing ratio
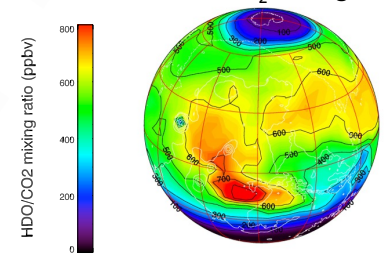

Fig. 14. Top: map of the line depth ratio of $\mathrm{HDO} / \mathrm{CO}_{2}$ retrieved from the TEXES data recorded on July 3, $2014\left(\mathrm{Ls}=156^{\circ}\right)$. The black circle corresponds to region $\mathrm{B}$ where the TEXES spectra were modeled (see text). Bottom left: TEXES map of the $\mathrm{HDO} / \mathrm{CO}_{2}$ mixing ratio inferred from the $\mathrm{HDO} / \mathrm{CO}_{2}$ line depth ratio. Bottom right: GCM synthetic map of the HDO mixing ratio (ppbv) calculated for the same observing conditions.

around $35 \mathrm{ppbv}$ in the afternoon (near the limb) between $0 \mathrm{~N}$ and $30 \mathrm{~N}$ latitude.

We have identified an area (B) corresponding to a high abundance of hydrogen peroxide. Region B corresponds to $15 \mathrm{~N}-30 \mathrm{~N}$ latitudes and a local hour of 13:00-15:00 pm. Figure 13 shows the TEXES spectrum integrated over this area, compared with synthetic models calculated using the method described above. The temperature profile used for Area B has temperatures of $241 \mathrm{~K}, 220 \mathrm{~K}, 173.5 \mathrm{~K}$, and $159 \mathrm{~K}$ at altitudes of $0 \mathrm{~km}, 10 \mathrm{~km}, 30 \mathrm{~km}$, and $50 \mathrm{~km}$ respectively. The surface pressure is 5.4 mbar and the surface brightness temperature is $265 \mathrm{~K}$; the profile is also shown in the Appendix (Fig. 17). Figure 13 shows that the best fit is obtained for a $\mathrm{H}_{2} \mathrm{O}_{2}$ mixing ratio of 30 ppbv. This result is discussed below (Sect. 4).

HDO

Figure 14 shows a map of the $\mathrm{HDO} / \mathrm{CO}_{2}$ line depth ratio inferred from the line depth maps shown in Fig. 11 (July 3, 2014), 


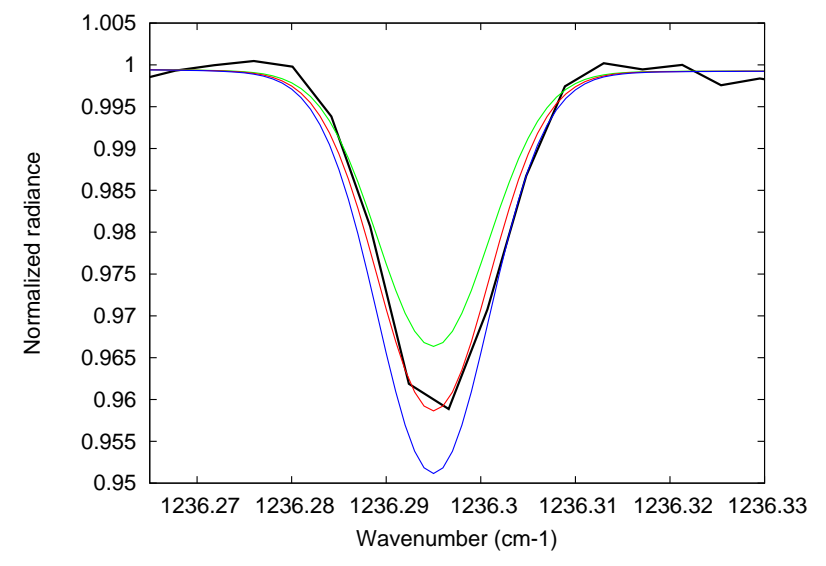

Fig. 15. Thick black line: TEXES spectrum of Mars in the vicinity of the HDO line at $1236.295 \mathrm{~cm}^{-1}$ (July 3, 2014; Ls $=156^{\circ}$ ), integrated over 9 pixels in region $\mathrm{B}$, compared with synthetic spectra. The continuum fluctuation in the TEXES data has been corrected by using the continuum on each side of each line and assuming a straight line between these two points. The airmass is 1.55 . Models: $\mathrm{H}_{2} \mathrm{O}=300$ ppbv (green), $375 \mathrm{ppbv}$ (red), $450 \mathrm{ppbv}$ (blue). The best fit is obtained for $\mathrm{H}_{2} \mathrm{O}=375$ ppbv.

and a map of the HDO mixing ratio, using the formula described in the Appendix. This map is compared with the GCM map of the HDO mixing ratio calculated under the same observing conditions. Because the HDO transition is significantly stronger than the $\mathrm{H}_{2} \mathrm{O}_{2}$ doublet, the map can be retrieved on a larger fraction of the disk (more than 50\%), from about 08:00 am to $15: 00 \mathrm{pm}$ in local time. Comparison between the TEXES and GCM maps is discussed in Sect. 4.

Figure 15 shows a comparison between the TEXES spectrum of HDO integrated over area B, and the synthetic models calculated using the atmospheric parameters used for the fit of the $\mathrm{H}_{2} \mathrm{O}_{2}$ doublet. The best fit is obtained for a HDO mixing ratio of $375 \mathrm{ppbv}$, corresponding to a column density of $22 \mathrm{pr}-\mathrm{nm}$. At this position, the GCM HDO map indicates a mixing ratio of about 600 ppbv (Fig. 14). This difference is discussed below (Sect. 4).

\subsection{Uncertainty analysis}

In this section, we evaluate the uncertainty associated with the determination of the $\mathrm{H}_{2} \mathrm{O}_{2}$ and $\mathrm{HDO}$ mixing ratios.

In the case of the maps of the mixing ratios (Figs. 6, 8, 12, and 14), the uncertainty associated with the method consisting of simply making the ratios of the $\mathrm{H}_{2} \mathrm{O}_{2}$ and $\mathrm{HDO}$ line depths to the $\mathrm{CO}_{2}$ line depth was first discussed in Encrenaz et al. (2008), and is analyzed in detail in the enclosed Appendix. Comparison with a grid of models covering a wide range of atmospheric parameters shows that the difference between the mixing ratio inferred from our method, compared with the mixing ratio derived from synthetic spectrum calculation, is no more than a few percent in most of the cases. In the case of $\mathrm{H}_{2} \mathrm{O}_{2}$, the departure due to the airmass is linear with the quantity $(\mathrm{am}-1.0)$ with, at the limb, a value of $10 \%$. This departure has been corrected (Figs. 6 and 11). In the case of HDO, the departure varies as a function of the $\mathrm{H}_{2} \mathrm{O}$ mixing ratio but is always less than $10 \%$ all over the disk (airmass lower than 3) and less than $20 \%$ at the limb (see Appendix).

In the case of the spectral fits (Figs. 7, 9, 13 and 15), we first estimated the noise level in the continuum of the spectra. From Figs. 2 and 3, which show the TEXES spectrum integrated over the Martian disk, we measure a 3- $\sigma$ (peak to peak) noise of $6 \times 10^{-3}$ at the $\mathrm{HDO}$ line and $5 \times 10^{-3}$ at the $\mathrm{H}_{2} \mathrm{O}_{2}$ line. In the case of the $\mathrm{A}$ and $\mathrm{B}$ spectra, the continuum is about 15 times lower, which translates into $\sigma$ values equal to $4.5 \times 10^{-3}$ and $4.0 \times 10^{-3}$ respectively. Our $\sigma$ estimates translate into mixing ratio fluctuations of $10 \mathrm{ppbv}$ for $\mathrm{H}_{2} \mathrm{O}_{2}$ (Figs. 8 and 13) and $60 \mathrm{ppbv}$ for HDO (Figs. 8 and 15). Taking into account the fact that we have two $\mathrm{H}_{2} \mathrm{O}_{2}$ lines, our results are the following:

Region A (March 1, 2014): $\mathrm{H}_{2} \mathrm{O}_{2}=20+/-7$ ppbv, HDO = $450+/-60$ ppbv $(45+/-6$ pr-nm);

Region B (July 3, 2014): $\mathrm{H}_{2} \mathrm{O}_{2}=30+/-7$ ppbv, $\mathrm{HDO}=$ $375+/-60$ ppbv (22 +/- 2.5 pr-nm).

We note that our $\mathrm{H}_{2} \mathrm{O}_{2}$ error bars are consistent with the limited quality of the fits (Figs. 8 and 13). Part of the misfit is due to a slight shift in the position of the $\mathrm{H}_{2} \mathrm{O}_{2}$ line at 1241.615, already noticed in our first analysis (Encrenaz et al. 2004) but other discrepancies, not fully understood, appear between the observed and modeled spectrum. In contrast, the two HDO fits are more satisfactory (Figs. 8 and 15). We note that the error bars derived from the signal-to-noise ratio of the TEXES data range between 23 and $35 \%$ for $\mathrm{H}_{2} \mathrm{O}_{2}$ and between 13 and $16 \%$ for HDO. In the case of $\mathrm{H}_{2} \mathrm{O}_{2}$, the error introduced by the use of the line depth ratio method is thus negligible as compared with the total error. In the case of HDO, adding quadratically an error of $10 \%$ to the uncertainties mentioned above, we derive the following values:

Region A (March 1, 2014): HDO = $450+/-75$ ppbv $(45+/-8$ pr-nm);

Region B (July 3, 2014): HDO = $375+/-70$ ppbv $(22+/-3$ pr-nm).

\section{Discussion}

\subsection{Hydrogen peroxide}

\subsubsection{March 1, $2014\left(\mathrm{Ls}=96^{\circ}\right)$}

The spatial distribution of $\mathrm{H}_{2} \mathrm{O}_{2}$ inferred by TEXES is in good general agreement with the GCM prediction, with a clear enhancement toward northern latitudes as expected at the time of northern summer solstice. There is, however, a discrepancy in the exact location of the maximum, which peaks at the north pole on the TEXES map while the GCM predicts a maximum at $60 \mathrm{~N}$ latitude. This discrepancy cannot be due to the seeing effect of the TEXES data as this effect, in contrast, tends to lower the observed flux at the limb. This difference is confirmed by the $\mathrm{H}_{2} \mathrm{O}_{2}$ mixing ratio measured in region $\mathrm{A}(20+/-7 \mathrm{ppbv})$, which is weaker than the predicted GCM value (30-35 ppbv). This discrepancy is presently unexplained.

\subsubsection{July $3,2014\left(\operatorname{Ls}=156^{\circ}\right)$}

According to GCM models, this is the season corresponding to the maximum global abundance of $\mathrm{H}_{2} \mathrm{O}_{2}$ at low latitudes (Lefèvre et al. 2008; Encrenaz et al. 2012). In the case of the July 3 observations, the $\mathrm{H}_{2} \mathrm{O}_{2}$ maximum calculated by the model is located around $30 \mathrm{~N}$ latitude at both northern limbs. As explained above, the nightside limb is not accessible to observations, so the northern sunlit limb is the only place where TEXES data can be compared with GCM predictions.

The $\mathrm{H}_{2} \mathrm{O}_{2}$ mixing ratio derived in site $\mathrm{B}(30+/-7$ ppbv, Fig. 13) is in good agreement with the GCM model, and the GCM map is also in agreement with the spatial distribution observed in this area (Fig. 12). The depletion of hydrogen peroxide 


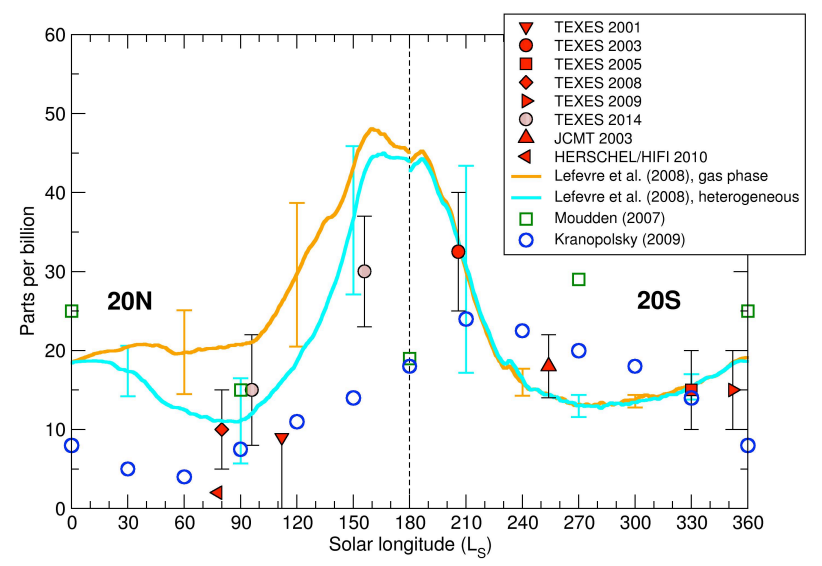

Fig. 16. Seasonal cycle of hydrogen peroxide on Mars integrated over the Martian disk. Observed regions are centered around $20 \mathrm{~N}$ during northern spring and summer, and around 20S during northern autumn and winter. Yellow: 3D GCM model considering only the gas phase. Blue: 3D GCM model considering heterogeneous chemistry on water ice grains. Blue circles: 1D model by Krasnopolsky (2009). Green squares: 1D model by Moudden (2007). The figure has been updated from Lefèvre et al. (2008) and Encrenaz et al. (2012).

toward the north pole and toward southern latitudes, expected from the GCM, is also observed in the TEXES data.

\subsubsection{Seasonal variations of hydrogen peroxide}

Seasonal variations of hydrogen peroxide, recorded with TEXES and other means (JCMT, Herschel/HIFI) between 2004 and 2010, were shown in Encrenaz et al. (2012). Northern latitudes (around a mean value of $20 \mathrm{~N}$ ) were observed during northern spring and summer, while southern latitudes around 20S were observed during northern autumn and winter. Results were compared with various photochemical models, including the 1D models of Moudden (2007) and Krasnopolsky (2009), and the GCM models developed assuming both homogeneous and heterogeneous chemistry. Our conclusion was that the observed data was in better agreement with the GCM heterogeneous model (Lefèvre et al. 2008; Encrenaz et al. 2012). However, no data were recorded between $\mathrm{Ls}=120^{\circ}$ and Ls $=180^{\circ}$, a season critical for distinguishing between different photochemical models.

The July 2014 data help us to fill this gap, while the March 2014 data provide a new point around northern summer solstice, also critical for distinguishing among models, for which contradictory results were obtained in the past. In the case of the March 2014 data, using Fig. 6, we first estimate a mean mixing ratio over the $20 \mathrm{~N}$ latitude range, noting that the disk center actually corresponds to this latitude. We derive a $\mathrm{H}_{2} \mathrm{O}_{2}$ diskaveraged mixing ratio of $15+/-7 \mathrm{ppb}$, in good agreement with the GCM value. In the case of the July 2014 data, we cannot estimate the mean TEXES value for a latitude of $20 \mathrm{~N}$ but, based on the good agreement of TEXES with the GCM in Region B, from the GCM map we use a mean value of $30+/-7$ ppbv over the $20 \mathrm{~N}$ latitude range.

Figure 16 shows the mean $20 \mathrm{~N}$ and $20 \mathrm{~S}$ variations of $\mathrm{H}_{2} \mathrm{O}_{2}$ as a function of the areocentric longitude Ls updated from the work of Lefèvre et al. (2008) and Encrenaz et al. (2012). It can be seen that, in spite of the relatively large error bars of the data and the models, the two new data points obtained in 2014 favor the heterogeneous model developed by Lefèvre et al. (2008). This model, initially based on the seasonal behavior of ozone in the Earth, was able to reproduce the ozone seasonal cycle on Mars, assuming that water ice clouds provide sites for uptaking ozone-destroying hydrogen radicals $\mathrm{HO}_{x}$. This mechanism leads to $\mathrm{H}_{2} \mathrm{O}_{2}$ abundances that are lower than in a simulation that only takes into account gas-phase chemistry.

The difference between the $\mathrm{H}_{2} \mathrm{O}_{2}$ contents in the homogeneous and heterogeneous chemistry models may be visible on their disk-integrated mixing ratios, as shown in Fig. 16, and also in their spatial distribution over the disk. For Ls $=96^{\circ}$ (March 2014), the ice clouds are expected to be at a maximum near the equator (Smith 2004), and so is the depletion of $\mathrm{H}_{2} \mathrm{O}_{2}$ in the heterogeneous model (Fig. 16). Such a depletion, with respect to higher northern latitudes, is actually observed with TEXES (Fig. 6). For Ls $=156^{\circ}$, in contrast, the water ice depletion at the equator is much less (Smith 2004), and the $\mathrm{H}_{2} \mathrm{O}_{2}$ depletion due to reactions on ice near the equator is much less pronounced, both from the observation (Fig. 12) and in the GCM (Fig. 16).

In spite of their relatively large error bars, the new TEXES data provide additional support to the heterogeneous chemistry model. A puzzling question remains, however: the upper limit of 3 ppbv recorded by Herschel/HIFI for Ls $=77^{\circ}$ (Hartogh et al. 2010) remains unexplained. The upper limit recorded by TEXES for $\mathrm{Ls}=112^{\circ}(10 \mathrm{ppbv}$, Encrenaz et al. 2002) is also surprising; however, the time exposure for this dataset was quite short, so the data quality was significantly lower than for the following runs. Nevertheless, there are still possibly interannual variations of hydrogen peroxide that need to be better understood.

\subsubsection{Vertical distribution of hydrogen peroxide}

As mentioned above, we have assumed in our study a constant vertical mixing ratio for hydrogen peroxide. However, photochemical models predict that $\mathrm{H}_{2} \mathrm{O}_{2}$ is essentially confined near the surface as it mimics the water behavior as a function of season (Clancy \& Nair 1996; Lefèvre et al. 2004; Encrenaz et al. 2012), following the variations of the hygropause which is quite low at both of the seasons observed here. As a result, the $\mathrm{H}_{2} \mathrm{O}_{2}$ mixing ratios retrieved in this study might be underestimated at the surface. However, photochemical models (Lefèvre et al. 2004) predict that the $\mathrm{H}_{2} \mathrm{O}_{2}$ cutoff is located between 10 and $20 \mathrm{~km}$, i.e., above the region probed by TEXES. Thus, the assumption of constant mixing ratio is expected to have a minor influence on our results.

\section{2. $\mathrm{HDO}$ and $\mathrm{H}_{2} \mathrm{O}$}

As in our previous analyses (Encrenaz et al. 2005, 2008, 2010), we have converted our HDO measurements into $\mathrm{H}_{2} \mathrm{O}$ mixing ratios for a comparison with earlier observations (Smith 2002, 2004) and GCM results. We first need to make an assumption of the mean $\mathrm{D} / \mathrm{H}$ ratio on Mars. Past observations indicate mean or localized enrichments (with respect to the terrestrial value, the Standard Mean Ocean Water SMOW) of $6+/ 3$ (Owen et al. 1989), $5.2+/-1.0$ (Krasnopolsky et al. 1997), 5.0 (Hartogh et al. 2011) and $6.0+/-1.0$ (Webster et al. 2013). Maps of D/H during northern spring were measured by Novak et al. (2011) and Villanueva et al. (2015) during northern spring, indicating a Martian D/H ratio around 7 times the terrestrial value; in addition, Villanueva et al. (2015) observed strong variations of the $\mathrm{D} / \mathrm{H}$ ratio over the disk (from about 2 to 9 times the SMOW value). In their model of the HDO cycle, Montmessin et al. forced the north polar cap reservoir with a deuterated content of 


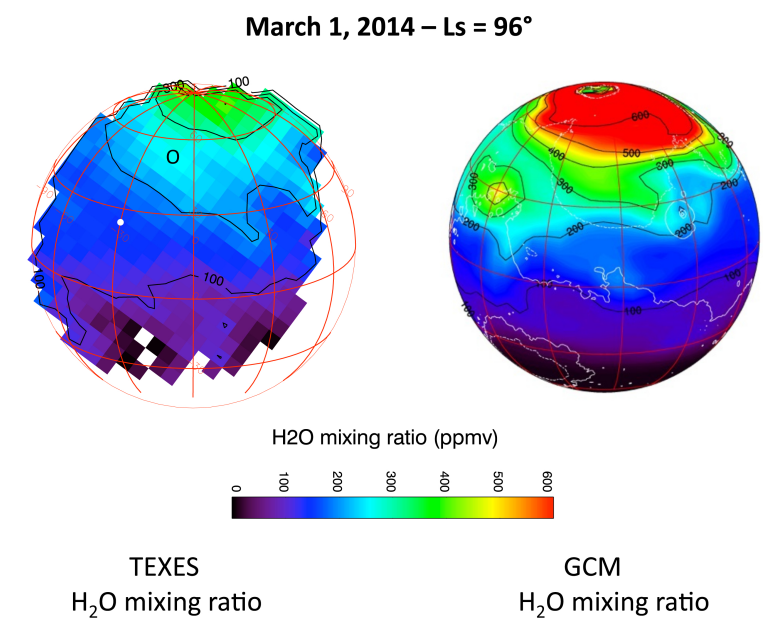

Fig. 17. Left: map of the $\mathrm{H}_{2} \mathrm{O} / \mathrm{CO}_{2}$ mixing ratio (in ppmv) retrieved from the TEXES data recorded on March 1, $2014\left(\mathrm{Ls}=96^{\circ}\right)$, converted from the $\mathrm{HDO} / \mathrm{CO}_{2}$ mixing ratio map (Fig. 8), assuming a Martian mean $\mathrm{D} / \mathrm{H}$ ratio of 5 times the terrestrial value. The black circle corresponds to region A where the TEXES spectra were modeled (see text). Right: GCM synthetic map of the $\mathrm{H}_{2} \mathrm{O}_{2} / \mathrm{CO}_{2}$ column-averaged mixing ratio (in ppmv) calculated for the same observing conditions.

\section{July 3, $2014-\mathrm{Ls}=96^{\circ}$}

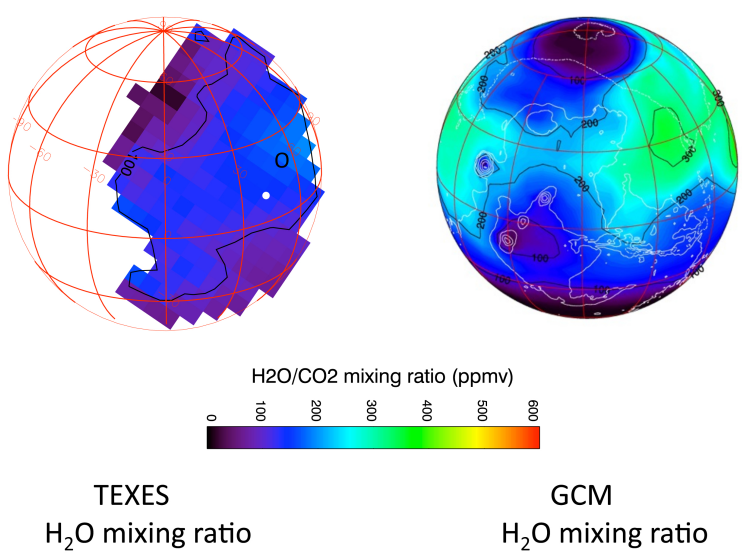

Fig. 18. Left: map of the $\mathrm{H}_{2} \mathrm{O} / \mathrm{CO}_{2}$ mixing ratio (in ppmv) retrieved from the TEXES data recorded on July 3, $2014\left(\mathrm{Ls}=156^{\circ}\right)$, converted from the $\mathrm{HDO} / \mathrm{CO}_{2}$ mixing ratio map (Fig. 14), assuming a Martian mean $\mathrm{D} / \mathrm{H}$ ratio of 5 times the terrestrial value. The black circle corresponds to region $\mathrm{B}$ where the TEXES spectra were modeled (see text). Right: GCM synthetic map of the $\mathrm{H}_{2} \mathrm{O}_{2} / \mathrm{CO}_{2}$ column-averaged mixing ratio (in ppmv) calculated for the same observing conditions.

5.6 times the terrestrial value. As a result, their mean planetaryaveraged $\mathrm{D} / \mathrm{H}$ ratio is 4.8 , with small variations with season (about $2 \%$ ) and moderate variations with latitude (about 10\%), except at the poles (up to 50\%).

In what follows, we convert our HDO maps using a mean $\mathrm{D} / \mathrm{H}$ of $5.0 \mathrm{wr}$ SMOW. This is consistent with our previous studies and allows us to compare our $\mathrm{HDO}$ and $\mathrm{H}_{2} \mathrm{O}$ maps with the ones produced by the GCM. However, we are aware that a more accurate determination of $\mathrm{D} / \mathrm{H}$ as a function of latitude, topography, and season needs to be achieved. Figures 17 and 18 show the TEXES maps of water vapor for March 2014 and July 2014, respectively, compared with the GCM maps calculated under the same conditions.

\subsubsection{March 1, $2014\left(\mathrm{LS}=96^{\circ}\right)$}

It can be seen from Fig. 8 that the two HDO maps, from TEXES and from the GCM, are generally consistent: as expected at the time of northern summer solstice, the HDO content is maximum around the north pole. There are some differences, however. The maximum mixing ratio at the north pole, as observed by TEXES, is about $25 \%$ weaker than expected by the model. In addition, the TEXES data do not reproduce the morphology shown at low latitudes by the GCM simulation. These differences also reflect in Fig. 17 where the agreement is satisfactory for low and middle latitudes, while the excess of the predicted water content versus the TEXES measurement is about 1.5 at $30-60$ northern latitudes, and up to a factor of 2 at the north pole.

\subsubsection{July 3, $2014\left(\mathrm{LS}=156^{\circ}\right)$}

Figure 14 shows that the HDO abundance measured by TEXES is significantly lower than the GCM predictions. Both TEXES and GCM maps show a maximum near the limb, in the evening and at northern mid-latitudes; however, the observed HDO mixing ratio is lower than the GCM predictions all over the observed area by about a factor of 1.5 to 2 . The same discrepancy (by a factor of about 2) is observed in the $\mathrm{H}_{2} \mathrm{O}$ maps for mid-latitudes in the evening.

\subsubsection{Vertical distribution of water vapor}

As mentioned above (Sects. 2.2 and 4.2.4), our retrieval of the water vapor mixing ratio assumes a constant vertical value, and thus does not account for condensation, which is especially efficient near northern summer solstice, close to the cold aphelion period. We note that the same approximation was used by Smith et al. (2000) and Smith (2002) in their reduction of the TES database. This effect is expected to lead to an underestimation of the water vapor mixing ratio at the surface, while the effect of cold aerosols over the hygropause should lead to the opposite effect, so both effects are expected to compensate.

\section{Conclusions}

The main conclusions of the present study can be summarized as follows:

- New TEXES observations were obtained in 2014 at the time of maximum water content (March 2014, Ls $=96^{\circ}$ ) and maximum hydrogen peroxide content at low latitudes (July 2014, $\mathrm{Ls}=156^{\circ}$ ). Maps of $\mathrm{H}_{2} \mathrm{O}_{2}$ obtained with TEXES are in good overall agreement with the predictions of the Global Climate Model (GCM). Maps of HDO are generally consistent with the GCM model, but indicate lower values (by a factor of about 1.5-2) in the regions where HDO is expected to be at a maximum.

- The new measurements of hydrogen peroxide are better fitted with the 3D GCM model which takes into account heterogeneous chemistry over water ice grains (Lefèvre et al. 2008).

- The July 2014 dataset illustrates the dependence of the retrieval of minor species on the local time. Before and around dawn, the temperature contrast between the surface and the atmosphere is not sufficient for weak transitions of minor species to be measured with enough precision. The temperature gradient between the surface and the atmosphere tends to be the highest in the afternoon, which is the time when the abundances of minor species can best be retrieved. 
Acknowledgements. T.E. and T.K.G. were visiting astronomers at the Infrared Telescope Facility, which is operated by the University of Hawaii under cooperative agreement no. NNX-08AE38A with the national Aeronautics and Space Administration, Science Mission Doctorate, Planetary Astronomy Program. We wish to thank the IRTF staff for the support of TEXES observations. T.K.G. acknowledges support of NASA Grant NNX14AG34G. T.E. and B.B. acknowledge support from CNRS and Programme National de Planétologie. T.F. acknowledges support from UPMC. T.E. acknowledges support from Jet Propulsion Laboratory as a Distinguished Visiting Scientist. We are grateful to G. Villanueva for very helpful comments regarding this paper.

\section{Appendix A}

In this Appendix, we investigate the validity of the line depth ratio method, i.e. the linearity of this parameter with the mixing ratio of the minor molecule $\left(\mathrm{H}_{2} \mathrm{O}_{2}\right.$ and $\left.\mathrm{HDO}\right)$. A first discussion was presented in Encrenaz et al. (2008) by considering a set of different atmospheric profiles and airmass conditions. Our conclusion was that the uncertainty associated with this method was always less than $10 \%$, except at the limb where it could reach $25 \%$. In the present study, we repeat this analysis and we describe it in detail, by considering more precisely the various atmospheric profiles associated with our observations. We consider first $\mathrm{H}_{2} \mathrm{O}_{2}$, then $\mathrm{HDO}$, and we analyze separately the effects associated with the atmospheric profile and with the airmass.

Changes in the thermal profile of Mars are associated with the season and with the local hour. Our two sets of observations span different local hours: from 09:00 to 17:00 on March 1, 2014 and from 07:00 to 15:00 on July 3, 2014. Outside these time intervals, the TEXES data, if they exist, cannot be used because the continuum level is too low (Figs. 4 and 10). On the basis of past observations (Smith et al. 2015) and GCM simulations (Forget et al. 1999), we have built a grid of thermal profiles that are representative of all possible configurations within the local time ranges of our observations. These five profiles are shown in Fig. A.1 and described in the figure caption.

\section{A.1. Hydrogen peroxide}

On the basis of the $\mathrm{H}_{2} \mathrm{O}_{2} / \mathrm{CO}_{2}$ line depth ratios measured on the TEXES data and our previous measurements, we analyse how this ratio varies when the $\mathrm{H}_{2} \mathrm{O}_{2}$ mixing ratio varies between 0 and $40 \mathrm{ppbv}$. We consider first the effect of the thermal profiles, then the effect of the airmass.

\section{A.1.1. Changes induced by the thermal profile}

We first show in Fig. A.2 the $\mathrm{H}_{2} \mathrm{O}_{2}$ and $\mathrm{CO}_{2}$ spectra for our five thermal profiles, corresponding to an airmass of 1.0. As expected, the lines are strongest when the temperature contrast between the surface and the atmosphere is highest (Profile 2) and weakest in the opposite case (Profile 5). Figure A.3 shows how the $\mathrm{H}_{2} \mathrm{O}_{2} / \mathrm{CO}_{2}$ line depth ratio varies as a function of the $\mathrm{H}_{2} \mathrm{O}_{2}$ mixing ratio. First, it can be seen that the relation is rigorously linear up to a mixing ratio of $40 \mathrm{ppbv}$. Second, the difference between the profiles is only $3 \%$ or less, except for Profile 5 for which the line depth ratio is higher by almost $20 \%$. This profile corresponds to a region at the limit of observability in the TEXES data of March 14 (late afternoon), where our results are limited by the weak signal of the continuum. We conclude that, in all regions where the continuum signal is strong (i.e. higher than $5 \mathrm{erg} / \mathrm{s} / \mathrm{cm} / \mathrm{sr} / \mathrm{cm}^{-1}$ ), the uncertainty associated with changes in the thermal profile is less than a few percent. In view of the error bar on the $\mathrm{H}_{2} \mathrm{O}_{2}$ mixing ratio (more than $20 \%$, see

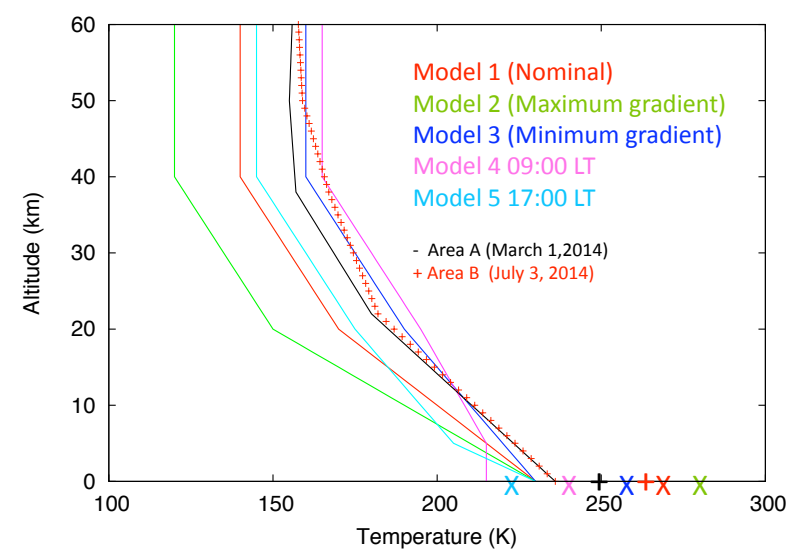

Fig. A.1. Thermal profiles used for the analysis of the line depth ratio method. Surface temperatures are indicated by Xs on the $x$-axis. A mean surface pressure of 6 mbars is assumed in all cases. The nominal profile (1, in red), with a temperature gradient of $-3 \mathrm{~K} / \mathrm{km}$ in the lower stratosphere and a surface temperature contrast $\mathrm{Ts}-\mathrm{T}(0)$ of $40 \mathrm{~K}$, is close to the GCM profile at the center of the disk in March 2014. The two next profiles ( 2 and 3 , in green and blue) show changes in the temperature gradients from $-4 \mathrm{~K} / \mathrm{km}$ to $-2 \mathrm{~K} / \mathrm{km}$ and surface temperature contrasts of $50 \mathrm{~K}$ and $30 \mathrm{~K}$ respectively; they illustrate two extreme cases of the temperature contrast between the surface and the atmosphere. The forth profile (4), in purple, is isothermal in the first $5 \mathrm{~km}$ with a temperature contrast of $25 \mathrm{~K}$. It corresponds to morning conditions in July 2014 and is close to the GCM profile at the center of the disk for this second run. Finally the fifth profile ( 5 , in light blue) illustrates late afternoon conditions (LT = 17:00) for the March 2014 observations, with a temperature inversion $[\mathrm{Ts}-\mathrm{T}(0)]$ of $-25 \mathrm{~K}$. The two profiles derived from the GCM for Areas A and B (see text, Sects. 3.1.2 and 3.2.2) are also shown in the figure (black curve: Area A; red crosses: Area B). The corresponding surface temperatures are indicated by plus signs on the $x$-axis. The corresponding surface pressures for Areas A and B are 8.3 mbar and 5.4 mbar, respectively.

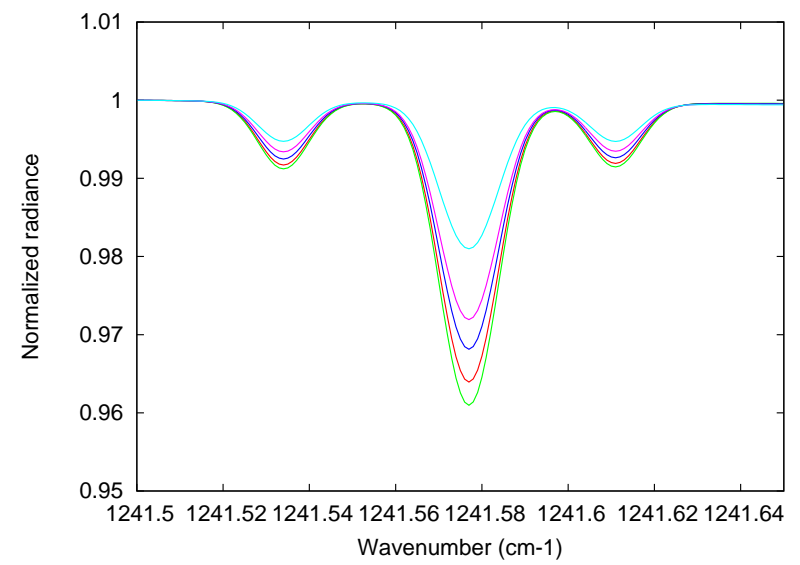

Fig. A.2. Spectra of the $\mathrm{H}_{2} \mathrm{O}_{2}$ and $\mathrm{CO}_{2}$ lines calculated with the five thermal profiles described above, for an airmass factor of 1.0 (disk.center), and for $\mathrm{a}_{2} \mathrm{O}_{2}$ mixing ratio of $30 \mathrm{ppbv}$. The color code is the same as for Fig. A.1. Red: nominal model (1); green: Model 2; blue: Model 3; purple: Model 4; light blue: Model 5. The two extreme absorption cases correspond to Model 2 (maximum absorption) and Model 5 (minimum absorption).

Sect. 3.3), this contribution is negligible when added quadratically with the other source (continuum noise).

\section{A.1.2. Changes induced by the air mass}

Figure A.4 shows, in the case of the nominal model (1), the variations of the $\mathrm{H}_{2} \mathrm{O}_{2}$ line depth ratio as a function of the 


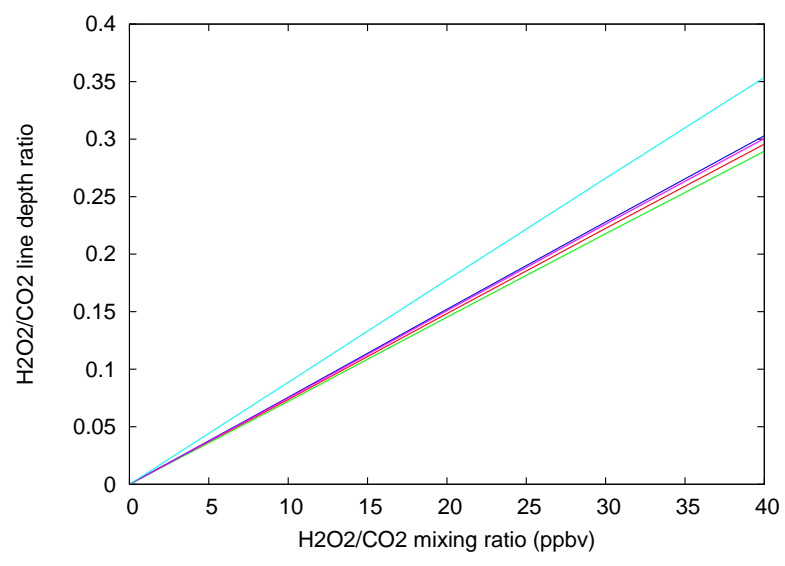

Fig. A.3. Variations of the $\mathrm{H}_{2} \mathrm{O}_{2}$ line depth ratio as a function of the $\mathrm{H}_{2} \mathrm{O}_{2}$ mixing ratio for the five different profiles. The color code is the same as for Figs. A.1 and A.2. All curves are exactly linear. Curves are compatible within 3\% for all profiles except Profile 5 (light blue), for which the curve differs by almost 20 per cent.

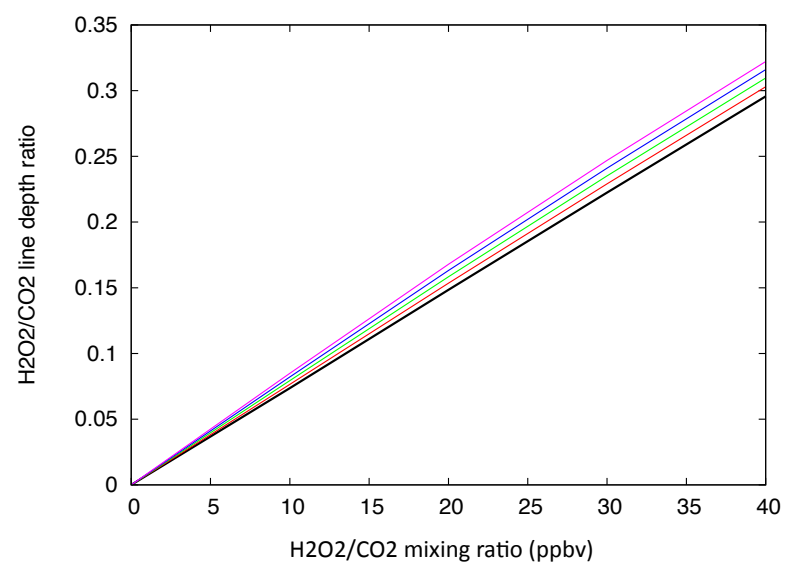

Fig. A.4. Variations of the $\mathrm{H}_{2} \mathrm{O}_{2}$ line depth ratio as a function of the $\mathrm{H}_{2} \mathrm{O}_{2}$ mixing ratio for the nominal profile (1), for different values of the airmass $(\mathrm{am}=1.0,2.0,3.0,4.0$ and 5.0). It can be seen that the departure from the am $=1$ curve is linear and proportional to the quantity $(\mathrm{am}-1.0)$.

$\mathrm{H}_{2} \mathrm{O}_{2}$ mixing ratio for five values of the airmass (from 1.0 to 5.0). It can be seen that the departure from the am $=1$ curve is linear, with a maximum value of $10 \%$ for am $=5$. We have checked that the same behavior is observed for all the other profiles. It is thus possible to correct this effect by applying a correction to the observed line depth ratios. We convert the line depth ratios (ldr) into mixing ratios (mr) using the following formula:

$\operatorname{mr}\left(\mathrm{H}_{2} \mathrm{O}_{2}\right)=\operatorname{ldr}\left(\mathrm{H}_{2} \mathrm{O}_{2}\right) \times 40 . / 0.29 /[1.0+(\mathrm{am}-1.0) \times 0.025]$,

where am is the airmass. This correction is applied in Figs. 6 and 12 (we note that the difference in the maps with and without the correction is almost undetectable).

\section{A.2. $H D O$}

The depths of two HDO lines used in the present study (1237.077 $\mathrm{cm}^{-1}$ in March 2014, $1236.295 \mathrm{~cm}^{-1}$ in July 2014) are deeper than the values of the $\mathrm{H}_{2} \mathrm{O}_{2}$ doublet. For our analysis, we use the $1237.077 \mathrm{~cm}^{-1}$ transition, which is stronger than the other by about a factor of 2. Figure A.5 shows the spectra of this HDO line calculated for the five profiles considered above, for an air mass of 1.0. Figure A.5 shows the same trend as in the

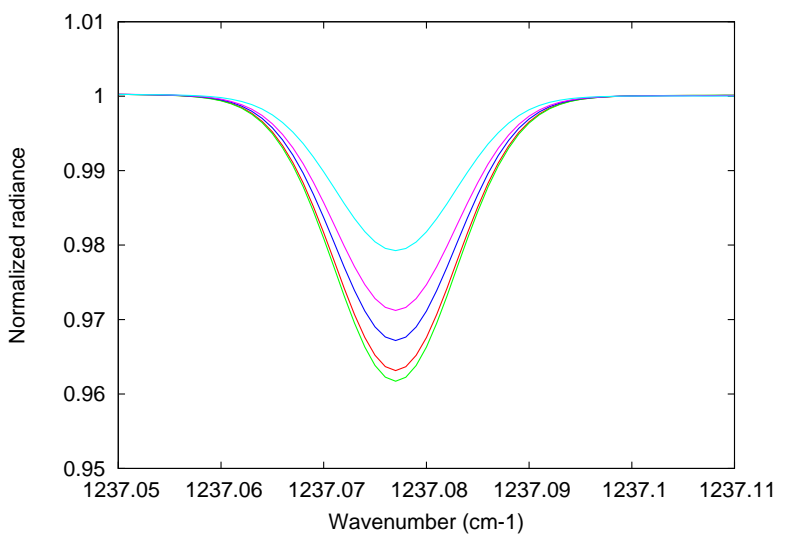

Fig. A.5. Spectra of the HDO line at $1237.077 \mathrm{~cm}^{-1}$, calculated with the five thermal profiles described above, for an airmass factor of 1.0 (disk.center). The color code is the same as for Fig. A.1. Red: nominal model (1); green: Model 2; blue: Model 3; purple: Model 4; light blue: Model 5. The two extreme absorption cases correspond to Model 2 (maximum absorption) and Model 5 (minimum absorption).

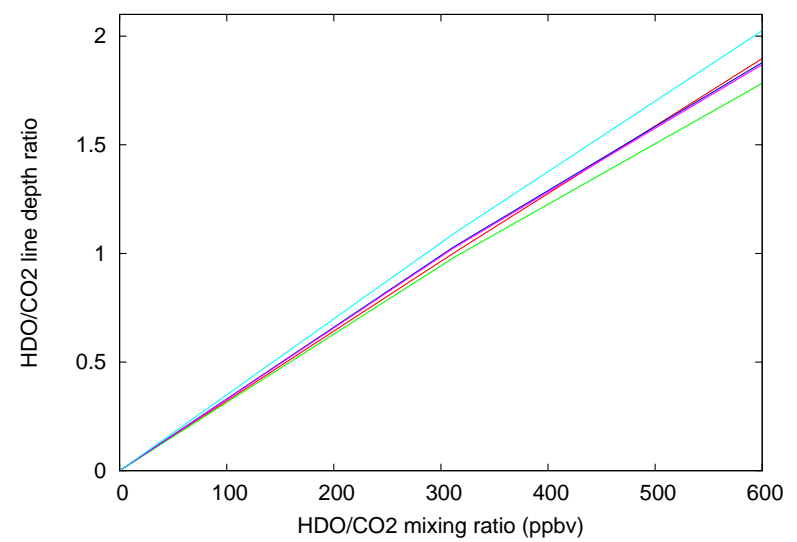

Fig. A.6. Variations of the HDO line depth ratio as a function of the HDO mixing ratio for the five different profiles. All curves are close to linear within $2 \%$. Models 2 (maximum surface-atmosphere temperature contrast) and 5 (minimum surface-atmosphere temperature contrast) represent the two extreme cases.

case of $\mathrm{H}_{2} \mathrm{O}_{2}$ (Fig. A.2), with a maximum depth corresponding to Model 2 (maximum gradient) and a minimum depth corresponding to Model 5 (17:00 LT).

Figure A.6 shows, for the five atmospheric models, the variation of the $\mathrm{HDO} / \mathrm{CO}_{2}$ line depth ratio as a function of the HDO mixing ratio, for an airmass value of 1.0. All curves are close to linearity within less than $2 \%$. Three models $(1,3,4)$ are close to the nominal profile by less than $2 \%$, while Profiles 2 and 5 differ by about $6 \%$ with respect to the nominal profile. We can thus conclude that the error induced by the atmospheric model is in all cases less than $10 \%$. To convert the HDO line depth ratio into a HDO mixing ratio, we used the following formula, derived from Fig. A.6:

$\operatorname{mr}(\mathrm{HDO})=\operatorname{ldr}(\mathrm{HDO}) \times 600.0 / 1.9$.

Figure A.7 shows the variations of the $\mathrm{HDO} / \mathrm{CO}_{2}$ line depth ratio as a function of the HDO mixing ratio for different values of the airmass. It is interesting to see that the behavior is different from the $\mathrm{H}_{2} \mathrm{O}_{2}$ case, in that the $\mathrm{HDO} / \mathrm{CO}_{2}$ line depth ratio is usually stronger than the $\mathrm{H}_{2} \mathrm{O}_{2} / \mathrm{CO}_{2}$ line depth ratio. For weak values of the HDO mixing ratio (lower than $150 \mathrm{ppbv}$ ), the slopes of the curves are, as for $\mathrm{H}_{2} \mathrm{O}_{2}$, proportional to the factor $(\mathrm{am}-1)$, 


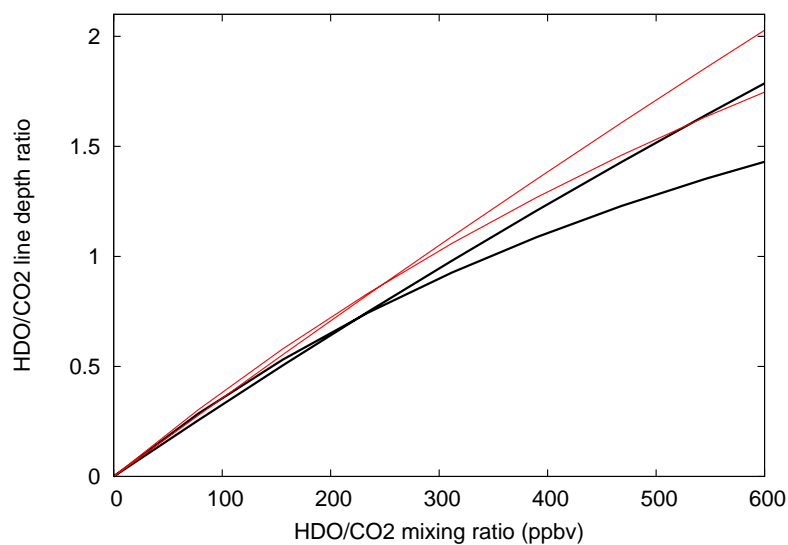

Fig. A.7. Variations of the $\mathrm{HDO} / \mathrm{CO}_{2}$ line depth ratio as a function of the HDO mixing ratio for two extreme profiles (black lines: Model 2; red lines: Model 5), for two different values of the airmass $(\mathrm{am}=1.0$ and 5.0). It can be seen that, for low values of the line depth ratio, the behavior is similar to the $\mathrm{H}_{2} \mathrm{O}_{2}$ case (Fig. A.4). The curves converge in a single point where this ratio is close to $0.7-0.9$, and diverge again for higher values of the line depth ratio.

with am being the airmass. However, when the $\mathrm{HDO} / \mathrm{CO}_{2}$ line depth ratio comes close to about 0.8 , all curves converge to a single point (for a HDO mixing ratio which slightly depends upon the model used) and diverge again for higher values of the HDO mixing ratio.

The maximum departure from linearity is $20 \%$ for an air mass of 5.0, in the case of a HD0 mixing ratio of 600 ppbv (higher than the values measured in our observations). In the case of the TEXES observations, with a disk diameter of $10 \mathrm{arcsec}$, the spatial resolution of 1 arcsec does not allow us to probe the limb at an airmass higher than 3.0. We thus conclude that, for any value of the $\mathrm{H}_{2} \mathrm{O}$ mixing ratio, the maximum uncertainty induced by our method is less than $10 \%$ anywhere on the disk and less than $20 \%$ near the limb.

\section{References}

Atreya, S. K., \& Gu, Z. G. 1995, Adv. Space Res., 16, 57

Christensen, P. R., Banfield, J. L., Hamilton, V. E., et al. 2001, J. Geophys. Res., 106,23823

Clancy, R. T., \& Nair, H. 1996, J. Geophys. Res., 101, 12785

Clancy, R. T., Sandor, B. J., \& Moriarty-Schieven, G. H. 2004, Icarus, 168, 116

Encrenaz, T., Greathouse, T. K., Bézard, B., et al. 2002, A\&A, 396, 1037 Encrenaz, T., Bézard, B., Greathouse, T. K., et al. 2004, Icarus, 170, 424 Encrenaz, T., Bézard, B., Owen, T., et al. 2005, Icarus, 179, 43 Encrenaz, T., Greathouse, T. K., Richter, M. J., et al. 2008, Icarus, 195, 547 Encrenaz, T., Greathouse, T. K., Bézard, B., et al. 2010, A\&A, 520, A33

Encrenaz, T., Greathouse, T. K., Lefèvre, F., et al. 2012, Plan. Space Sci., 68, 3

Forget, F., Hourdin, F., Fournier, R., et al. 1999, J. Geophys. Res., 104, 24155 Hartogh, P., Jarchow, C., Lellouch, E., et al. 2010, A\&A, 521, L49

Hartogh, P., Jarchow, C., de Val-Borro, M., et al. 2011, Fourth International Workshop on the Mars Atmosphere: Modelling and observations, Paris, 8-11 February. Published on line at http://www-mars-1md. jussieu.fr/ paris2011/program.html, 44

Jacquinet-Husson, N., Scott, N., Chedin, A., et al. 2008, J. Quant. Spectr. Rad. Transf., 109, 1043

Krasnopolsky, V. A. 2009, Icarus, 201, 564

Lacy, J. H., Richter, M. J., Greathouse, T. K., et al. 2002, Pub. Astron. Soc. Pac., 114,153

Lefèvre, F., Lebonnois, S., Montmessin, F., \& Forget, F. 2004, J. Geophys. Res., E07004, DOI: 10.1051/0004-6361/2004JE002268

Lefèvre, F., Bertaux, J.-L., Clancy, R. T., et al. 2008, Nature, 454, 971

Montmessin, F., Fouchet, T., \& Forget, F. 2005, J. Geophys. Res., 110, 03006

Moudden, Y. 2007, Plan. Space Sci., 55, 2137

Novak, R. E., Mumma, M. J., \& Villanueva, G. L. 2011, Plan. Space Sci., 59, 163

Owen, T., Lutz, B. L., de Bergh, C., \& Maillard, J.-P. 1989, Science, 240, 1767

Parkinson, T. D., \& Hunten, D. M. 1972, J. Atmos. Sci., 29, 1380

Rothman, L. S. 1986. Appl. Opt., 25, 1795

Smith, M. D. 2002, J. Geophys. Res., 107, 25

Smith, M. D. 2004, Icarus, 167, 148

Smith, M. D., Banfield, J. P., \& Christensen, P. R. 2000, J. Geophys. Res., 105, 9589

Smith, M. D., Bougher, S., Encrenaz, T., Forget, F., \& Kleinboehl, A. 2015, in The atmosphere and Climate of Mars (Cambridge University Press)

Villanueva, G., Mumma, M. J., Novak, R. E., et al. 2015, Science, submitted Webster, C. R., Mahaffy, P. R., Flesch, G. J., et al. 2013, Science, 341, 260 